\title{
Convection-permitting fully coupled WRF-Hydro ensemble simulations in high mountain environment: impact of boundary layer- and lateral flow parameterizations on land-atmosphere interactions
}

\author{
Zhenyu Zhang $^{1,2}$ (D) Joel Arnault ${ }^{1} \cdot$ Patrick Laux $^{1,2} \cdot$ Ning Ma $^{3} \cdot$ Jianhui Wei $^{1} \cdot$ Shasha Shang $^{4} \cdot$ Harald Kunstmann $^{1,2}$
}

Received: 20 February 2021 / Accepted: 6 November 2021 / Published online: 18 November 2021

(c) The Author(s) 2021

\begin{abstract}
Numerical climate models have been upgraded by the improved description of terrestrial hydrological processes across different scales. The goal of this study is to explore the role of terrestrial hydrological processes on land-atmosphere interactions within the context of modeling uncertainties related to model physics parameterization. The models applied are the Weather Research and Forecasting (WRF) model and its coupled hydrological modeling system WRF-Hydro, which depicts the lateral terrestrial hydrological processes and further allows their feedback to the atmosphere. We conducted convection-permitting simulations (3 km) over the Heihe River Basin in Northwest China for the period 2008-2010, and particularly focused on its upper reach area of complex high mountains. In order to account for the modeling uncertainties associated with model physics parameterization, an ensemble of simulations is generated by varying the planetary boundary layer (PBL) schemes. We embedded the fully three-dimensional atmospheric water tagging method in both WRF and WRF-Hydro for quantifying the strength of land-atmosphere interactions. The impact of PBL parameterization on land-atmosphere interactions is evaluated through its direct effect on vertical mixing. Results suggest that enabled lateral terrestrial flow in WRF-Hydro distinctly increases soil moisture and evapotranspiration near the surface in the high mountains, thereby modifies the atmospheric condition regardless of the applied PBL scheme. The local precipitation recycling ratio in the study area increases from 1.52 to $1.9 \%$ due to the description of lateral terrestrial flow, and such positive feedback processes are irrespective of the modeling variability caused by PBL parameterizations. This study highlights the non-negligible contribution of lateral terrestrial flow to local precipitation recycling, indicating the potential of the fully coupled modeling in land-atmosphere interactions research.
\end{abstract}

Keywords Land-atmosphere interactions · Coupled WRF-Hydro model · Evaporated water tagging · Lateral flow · Precipitation recycling $\cdot$ Heihe River Basin

Zhenyu Zhang

zhenyu.zhang@kit.edu

1 Institute of Meteorology and Climate Research (IMK-IFU), Karlsruhe Institute of Technology, Campus Alpin, Garmisch-Partenkirchen, Germany

2 Institute of Geography, University of Augsburg, Augsburg, Germany

3 Key Laboratory of Water Cycle and Related Land Surface Processes, Institute of Geographic Sciences and Natural Resources Research, Chinese Academy of Sciences, Beijing, China

4 Key Laboratory of Western China's Environmental Systems (Ministry of Education), College of Earth and Environmental Sciences, Lanzhou University, Lanzhou, China

\section{Introduction}

Climate change influences global and regional hydrological variabilities and affects water resource supplies, and thus is essential for the environment and human development (Immerzeel et al. 2010; Vörösmarty et al. 2000). High-resolution regional climate modeling has shown the distinct capability in addressing research issues related to climate and hydrological applications. Regional climate models (RCMs) not only produce reliable added value at higher temporal-spatial resolution (Knist et al. 2018; Qiu et al. 2019; Solman and Blázquez, 2019), but also incorporate internally consistent water and energy exchanges throughout the land-atmosphere interface (Campbell et al. 2019; Knist et al. 2017; Smirnova et al. 2016). 
It has been pointed out that the land surface processes require a precise description in numerical weather and climate modeling (Betts and Silva Dias 2010; Koster et al. 2010; Ma et al. 2017; Santanello et al. 2018; Senatore et al. 2015). As land surface models (LSMs) integrated in RCMs usually have a crude representation of terrestrial water movements (Clark et al. 2015), one state-of-the-art focus in recent years has arisen on fully coupled atmospherichydrological modeling systems (Butts et al. 2014; Davison et al. 2018; Lahmer et al. 2020; Larsen et al. 2014; Ning et al. 2019; Rummler et al. 2019; Senatore et al. 2015; Zhang et al. 2019). Shrestha et al. (2014) employed the coupled Terrestrial Systems Modeling Platform (Gasper et al. 2014) for the North Rhine-Westphalia region in Germany. They found that the surface and groundwater processes enhanced the redistribution of moisture to dry soils, thereby influencing the exchange fluxes distribution and atmospheric boundary layer development. By coupling the hydrological model PROMET with Mesoscale Model version 5 (MM5), Zabel et al. (2012) noticed that the surface hydrological processes can influence evapotranspiration and precipitation either positively or negatively in central Europe, depending on prevailing hydrological conditions. Later on, Zabel and Mauser (2013) indicated that the coupled modeling improved nearsurface temperature simulation in the Upper Danube catchment. By using the Weather Research and Forecasting (WRF) model and its coupled hydrological model system WRF-Hydro, many studies illustrated that the near-surface lateral hydrological processes including overland flow and subsurface flow influence the regional climate, water cycle, and land-atmosphere feedbacks. In southern Italy, Senatore et al. (2015) investigated the impact of lateral terrestrial flow on surface hydrometeorological variables, and found that the latent heat fluxes were increased and the precipitation was influenced modestly. Arnault et al. (2016b) concluded that the impact on precipitation depends on the size of the analyzed area. Gao et al. (2006) and Zhang et al. (2019) performed the coupled simulations for short-term and longterm scale over high-elevation and complex terrain region in the northeastern Tibet Plateau. Their results demonstrated the influence of the lateral hydrological processes not only on the near-surface atmosphere, but also on the joint atmospheric-terrestrial water balance. Over the central Europe, Arnault et al. (2018) and Rummler et al. (2019) employed ensemble simulations during the summer season, and confirmed the importance of lateral flow description in regional atmospheric modeling via precipitation spread and regional local recycling. All of the above studies demonstrated the capability of fully coupled models in representing complex interaction between climate and land surface processes.

Uncertainties broadly exist in regional climate modeling related to model physics parameterization, internal variabilities, and external forcing (e.g., Braun and Tao
2000; Crétat et al. 2012; Klein et al. 2015; Laux et al. 2017). Multiple planetary boundary layer (PBL) parameterization schemes are available in numerical models, which are known to have a broad impact on RCM applications. In India, Gunwani and Mohan (2017) found that the PBL scheme is sensitive to downscaled meteorological fields over different climatic zones in WRF simulations. Likewise, many studies compared different PBL parameterization in meteorological condition prediction, by aiming to ascertain an appropriate PBL scheme for specific geographical regions (e.g., Avolio et al. 2017; GarcíaDíez et al. 2013; Hu et al. 2010). Over a coastal mountainous region in Canada, Onwukwe and Jackson (2020) conducted yearlong WRF simulations and found that the disparities in mixing strengths among PBL schemes were more considerable in summer than in winter, depending on moist stable conditions and airflow direction. Given that the PBL scheme adopts assumptions concerning mass, moisture, and energy transport from the land surface to the low atmosphere, uncertainties associated with the PBL parameterization could directly relate to land-atmosphere interactions. In the framework of fully coupled atmospheric-hydrological model systems, studies on the effects of different PBL parameterization schemes are usually lacking.

Precipitation originating from local evapotranspiration source is known as precipitation recycling, which has been actively used as a diagnostic measure of land-atmosphere interaction (Eltahir and Bras 1996; Trenberth 1999; van der Ent et al. 2013). The E-tagging method initially 'tags' the water vapor evaporated from the land surface, then treats the tagged moisture in the same way as all moisture does in the RCMs, and follows it in space and time until it precipitates. It considers the source-sink relations through all physical processes and relaxes the vertical-mixing assumption of other precipitation recycling measures (Arnault et al. 2016a; Insua-Costa and Miguez-Macho, 2018). Therefore, it is thought to be the most physically realistic way to access the recycled precipitation quantity, thus allowing for detecting small perturbation-induced changes at the land-atmosphere interface (Arnault et al. 2019; Dominguez et al. 2016; Zhang et al. 2019). For example, by incorporating the E-tagging method with MM5, Wei et al. (2015) investigated the annual cycle of the contribution of evaporation to precipitation for the Poyang Lake region in China, emphasizing the importance of land surface characteristics in the atmospheric hydrological cycle. Knoche and Kunstmann (2013) and Arnault et al. (2016a) traced the evaporated moisture pathways in West Africa, and they revealed the effect of vertical wind shear to regional precipitation recycling. On a large scale, Yang and Dominguez (2019) and Gao et al. (2020) employed a tagging-enabled WRF model for 
South America and Tibetan Plateau respectively, highlighting the effects of land surface conditions on recycled precipitation. These studies confirmed the ability of the E-tagging method to quantitatively assess land-atmosphere interactions.

Understanding the interactions between the atmospheric, land surface and hydrological processes is of great importance in complex mountain terrain. This is particularly true for the high mountain environment, which is considered as the nature's water tower while is experiencing more rapid climate change (Immerzeel et al. 2010; Pepin et al. 2015). The Heihe River Basin (HRB) is such an environment. It is located in Northwestern China, stretching from Tibetan Plateau to Mongolia, and suffering from water shortage and ecosystem deterioration problems (Cheng et al. 2014). In the upper reach of HRB, where the mountain elevation is particularly high, the water availability has been declared to be significantly sensitive to climate change ( $\mathrm{Li}$ et al. 2020; Luo et al. 2016; Ma et al. 2019; Zhang et al. 2016). The hydrological cycle in this arid alpine area and its connection to climate change still needs to be further understood, which requires a joint assessment of land-atmosphere interaction processes with a complex coupled modeling system (Zhang et al. 2019). Therefore, within the context of improving terrestrial hydrological processes in regional climate modeling, it is important to further understand the role of terrestrial water flow on land-atmosphere interactions in such an arid, high mountain environment area like HRB. An improved understanding can be achieved with the above-mentioned fully coupled atmospheric-hydrological modeling, by considering physics parameterization uncertainties and the quantification of the interactions strengthen with the E-tagging approach.

For this purpose, we use the newly developed E-tagging method embedded in the standard WRF and fully coupled WRF-Hydro model, and carry out ensemble simulations for the HRB region by varying PBL parameterizations. The main goals of this study are: (1) to assess the impact of lateral terrestrial flow on the simulation of surface hydrometeorological variables and land-atmosphere interactions, (2) to evaluate to what extent the PBL parameterization influences land-atmosphere interactions, and (3) to identify the respective impact of lateral terrestrial flow and the PBL parameterization uncertainties in a fully coupled modeling approach. The analyses of land surface-precipitation feedback processes (Asharaf et al. 2012; Schär et al. 1999) and precipitation recycling based on E-tagging are used as quantitative measures. To our knowledge, this is the first effort performed in regional climate modeling to consider uncertainties in the evaporated water tracing method originating from model physics parameterizations.

In the following, Sect. 2 briefly describes the study region and used datasets. In Sect. 3, the model descriptions and setup, as well as the ensemble strategy and quantitative methods are addressed. The results of ensemble modeling are discussed in Sect. 4, and the conclusions are summarized in Sect. 5.

\section{Study region and dataset}

The Heihe River Basin (HRB) is the second-largest inland river basin in China, covering an area of approximately $143,000 \mathrm{~km}^{2}$. The river starts from the Qilian Mountain in the northern Tibetan Plateau and disappears at two terminal lakes in the Gobi Desert. From the upstream mountains to the desert in downstream, the elevation decreases from 5500 to $1000 \mathrm{~m}$ (Fig. 1b), and the annual precipitation decreases from 550 to $50 \mathrm{~mm}$. The water vapor transport over HRB is mainly controlled by the middle-latitude westerly wind and polar north wind, with the weakened East Asian summer monsoon obstructed by the Qilian Mountains in the upstream (Wang et al. 2004; Wang et al. 2018a, b). Therefore, the precipitation in HRB shows large seasonal and spatial variability, with more than $80 \%$ precipitation occurring from May to September and $70 \%$ precipitation over the upper mountains ( $\mathrm{Li}$ et al. 2018a). Due to the steep terrain gradients (Fig. 1b) and climate characteristics, the natural landscape and hydrological conditions show an obvious spatial heterogeneity (Cheng et al. 2014). The upper reach of HRB is a typical alpine environment, where the main landscape is covered by alpine meadow, with the annual air temperature between $-3{ }^{\circ} \mathrm{C}$ and $0{ }^{\circ} \mathrm{C}$. The middle reach of HRB is spatially fragmentarily covered with lower oasis and dryland cropland. In this area, the river water and groundwater are largely consumed by irrigation water withdrawal. The downstream of HRB is vastly covered by the sand and gravel deserts plus certain riparian ecosystems. The climate is extremely dry, with annual precipitation less than $50 \mathrm{~mm}$ and potential evapotranspiration greater than $1000 \mathrm{~mm}(\mathrm{Ma}$ et al. 2014). The ecological system over the middle and downstream of HRB is threatened by an increase of water consumption, and is significantly dependent on upstream hydrological variability under rapid climate change (Cheng et al. 2014; Zhang et al. 2016). Therefore, this study particularly focuses on the upper reach of HRB (upper HRB) outlet at the Yingluoxia hydrological gauge (1634 $\mathrm{m}$ a.s.1.). The upper HRB is entirely situated within the Qilian Mountains, with a drainage area of $10,009 \mathrm{~km}^{2}$. Two additional hydrological gauges, located at Qilian (2590 m a.s.1.) and Zhamashike (2635 $\mathrm{m}$ a.s.l), measure the streamflow of eastern and western tributaries in the upper HRB (Fig. 1c).

The China Meteorological Forcing Dataset (CMFD), the Global Land Evaporation Amsterdam Methodology (GLEAM) dataset, and soil moisture dataset of European Space Agency's Climate Change Initiative (ESA CCI) are 
(a)

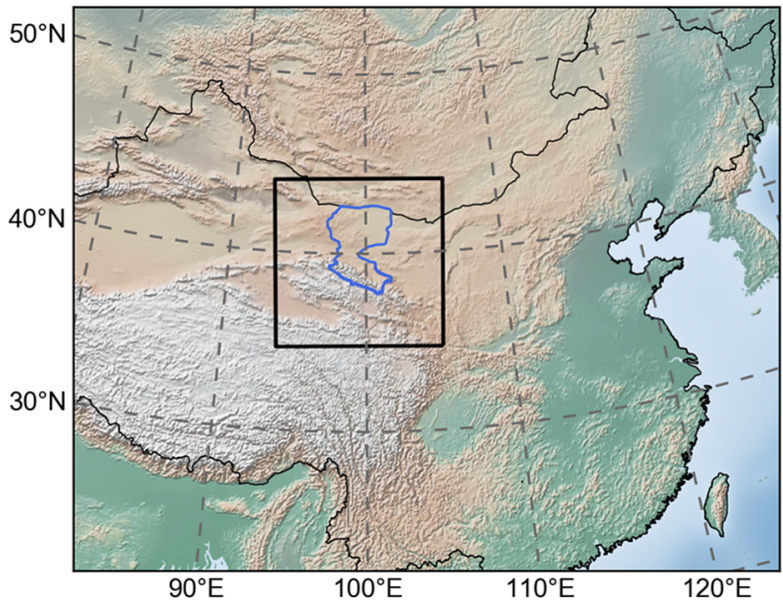

(b)

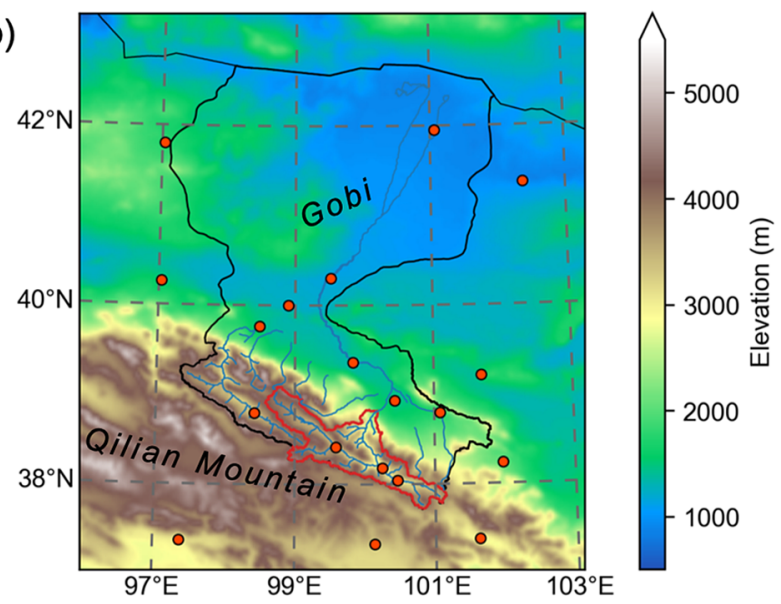

(c)

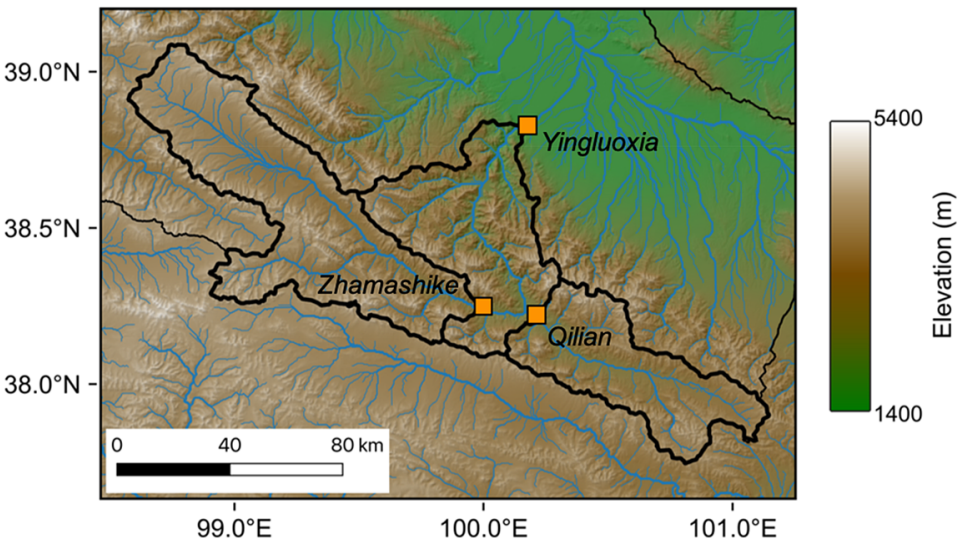

Fig. 1 a Geographic location of the Heihe River Basin and the location of WRF/WRF-Hydro model domain. b Terrain topography and river network of the drainage of Heihe River Basin, with nearby meteorological stations shown in red cycles. c Zoom of the topog- raphy, stream channels and the discharge gauges (orange rectangles) described in the 300-m high resolution WRF-Hydro routing subgrid for the upper Heihe River Basin used for evaluating the modeling results. The CMFD data was constructed by merging 740 in-situ China Meteorological Administration (CMA) stations with various advanced retrospective analyses data resources (He et al. 2020). This product provides gridded meteorological analysis over China with spatial and temporal resolutions of $0.1^{\circ}$ and $3 \mathrm{~h}$, respectively. Extensive studies suggested that CMFD accurately represents the meteorological conditions within and surrounding the HRB region (Pan et al. 2014; Yang et al. 2017b). In this study, CMFD is used for the validation of air temperature and precipitation, and for offline hydrological model driving (see Sect. 3.1). The GLEAM dataset (Martens et al. 2017) is the global evapotranspiration product based on remote sensing observation, with a spatial resolution of $0.25^{\circ}$. Based on the point-validation of GLEAM dataset across China via eddy covariance measurements, Yang et al. (2017a) confirmed the capability of GLEAM in representing monthly and spatial variations of evapotranspiration around upper HRB. The soil moisture from ESA CCI is the remotely sensed surface soil moisture combined from active and passive microwave sensors measurements, with a spatial resolution of $0.25^{\circ}$ (Gruber et al. 2019). For the site-based measurements, 18 meteorological stations within and surrounding the HRB (Fig. 1b) collected by CMA stations and Heihe Watershed Allied Telemetry Experimental Research project ( $\mathrm{Li}$ et al. 2013) are used for further verifying air temperature and precipitation. Daily streamflow observation records from 3 hydrological gauges in upper HRB, shown in Fig. 1c, are provided by the Hydrological Bureau of Gansu Province. The missing records from meteorological stations are linearly interpolated with the nearby stations. The streamflow records affected by dry season dam operation at Yingluoxia gauge are reconstructed using linear-line fit with two upstream gauge records. 


\section{Modeling experiments and methods}

\subsection{WRF and WRF-Hydro setup}

The advanced research WRF model (Skamarock and Klemp 2008) version 3.7 and its Hydrological modeling system WRF-Hydro (Gochis et al. 2015) are employed for regional atmosphere-hydrology simulations to address the research objectives of this study. WRF is a numerical meteorological and climate model that is widely used in weather and climate research as well as operational applications (Powers et al. 2017). WRF-Hydro affords a set of supplementary hydrological components to the WRF model, which enables the capability of lateral redistribution of the hydrological condition at the land surface (Gochis et al. 2015). All WRF and WRF-Hydro simulations are run in a single-domain configuration, covering the whole HRB and centering at the upper HRB (Fig. 1a). Acknowledging that the refined model grid improves orography representation over highly complex terrain, thereby offering added values in simulated surface fields (e.g., Fosser et al. 2014; Karki et al. 2017; Woodhams et al. 2018), all simulations are performed at a convection-permitting resolution of $3 \mathrm{~km}$ with $350 \times 350$ grid points. This high resolution excludes the uncertainties from cumulus parameterization, thus allowing for a more realistic simulated soil moisture-precipitation feedback (Prein et al. 2015; Taylor et al. 2013). The vertical coordinate is a hybrid terrain-following coordinate with 40 levels and pressure top at $20 \mathrm{hPa}$. The atmospheric lateral boundary conditions are provided by the operational analysis from the European Center for Medium-Range Weather Forecasts (ECMWF), with $0.125^{\circ}$ spatial resolution and 6-h intervals. The model physics adopted in this study includes the WRF single-moment 6-class (WSM6) microphysics scheme (Hong and Lim 2006), the Rapid Radiative Transfer Model longwave radiation scheme (Mlawer et al. 1997), and the Dudhia shortwave radiation scheme (Dudhia 1989). The different PBL schemes used for turbulence parameterization are described in Sect. 3.2

The land surface static characteristics are replaced with the accurate localized dataset, acknowledging their noticeable impact on atmospheric modeling in the study area (Gao et al. 2008; Meng et al. 2009; Wen et al. 2012). The land cover map is updated with the Multi-source Integrated Chinese Land Cover Map (Ran et al. 2012), and the soil texture map is adapted from the Chinese 1: 1,000,000 scale Soil Map and Harmonized World Soil Database (HWSD) version 1.2. The Noah-LSM scheme is used for parameterizing lower boundary interactions in the land surface (Chen and Dudhia 2001). In the WRF model, Noah-LSM only considers vertical water and energy exchanges in a 4-layer soil column within a 2-m soil depth.
The above model configurations are the same in WRF and coupled WRF-Hydro simulations. In WRF-Hydro, a separated 300-m hyper-resolution subgrid is prepared with WRF-Hydro Pre-processing Tool using the hydrological data and maps based on Shuttle Elevation Derivatives at multiple Scales (HydroSHEDS; Lehner et al. 2008). At each WRF model timestep, hydrological variables including surface water amount and soil moisture are disaggregated from the 3-km WRF grid to the 300-m hydro subgrid. Afterward, additional hydrological processes including lateral subsurface flow routing, overland flow routing, and channel water routing are resolved in this hydro subgrid, resulting in an updated surface state variable. The drainage water from the soil bottom is collected in a groundwater bucket for each basin area, and is used for baseflow calculation via an exponential function. We note that the water routed in the channel and collected in the bucket has no further feedback to the land surface modeling. A detailed description of the water routing schemes and baseflow routine in WRFHydro is available in Gochis et al. (2015). Succeeding the above hydrological procedures, surface water amount and soil moisture content on the fine hydro subgrid are linearly averaged back to the coarse WRF grid. Therefore, the land surface condition modulated by lateral terrestrial flow feeds back to WRF atmospheric processes at the next iteration of the Noah-LSM.

Calibrating the hydrological parameters is relevant to the realistic representation of terrestrial water processes in hydrological modeling. Driven by the observational-based CMFD dataset, the WRF-Hydro model is calibrated in its offline mode using observed daily streamflow at the Yingluoxia gauge. After model calibration, the Nash-Sutcliffe efficiency and Kling-Gupta efficiency (Gupta et al. 2009) of the simulated streamflow reach the values of 0.6 and 0.79 , respectively. The calibration procedure has been elaborated in Yucel et al. (2015) and detail of calibration results has been discussed in Zhang et al. (2019). The calibrated parameter set is therefore used in fully coupled WRF-Hydro simulations.

\subsection{PBL schemes and experimental strategy}

Three PBL schemes in WRF and WRF-Hydro are used for investigating modeling sensitivity to turbulence parameterization: the Yonsei University (YSU) scheme, the MellorYamada-Janjic (MYJ) scheme, and the Asymmetrical Convective Model version 2 (ACM2) scheme. These three PBL schemes are chosen as they have been extensively considered in turbulence parameterization uncertainty studies (Arnault et al. 2018; García-Díez et al. 2013; Gómez-Navarro et al. 2015; Gunwani and Mohan, 2017; Hu et al. 2010). The YSU scheme is a first-order scheme that uses the nonlocal eddy diffusivity coefficient to explicate turbulent fluxes (Hong 
et al. 2006). The MYJ scheme is a local closure scheme and it uses a 1.5-order turbulence model with a prognostic equation for the turbulent kinetic energy (Janjić 1994). ACM2 uses a combination of nonlocal upward convective mixing and local downward mixing, and treats nonlocal fluxes using a transilient matrix (Pleim 2007). In this study, all the WRF and coupled WRF-Hydro simulations are configured with the model setups in Sect. 3.1 and run three times, one for each of these three PBL schemes. This gives a model ensemble of six members, that are three WRF members and three WRF-Hydro members (Table 1).

A schematic view of model ensemble members is provided in Fig. S1. When intercomparing the ensemble members in Fig. S1, the comparisons in horizontal (orange line) indicate the model uncertainties related to PBL schemes, and the comparisons in vertical (blue line) express the influences related to lateral terrestrial flow. In the following, we call Hydro-ensembles the ones which use only WRF members (WRFS) or WRF-Hydro members (WRFH). Then, we call PBL-ensembles the ones which use only one PBL scheme.

For all ensemble simulations, the initial soil conditions is spun-up by the 2-year WRF simulation with the ACM2 PBL scheme, ensuring their comparability in the following analyses. All the simulations are performed from 2008 to 2010, which allows to account for the interannual modeling variabilities.

\subsection{Evaporated water tagging method}

The physically realistic method to trace online the water originating from evapotranspiration, known as E-tagging, is used for diagnosing and quantifying the land-atmosphere interactions in the study. This method was firstly technically realized in the German Weather Service's hydrostatic high-resolution model (HRM) by Sodemann et al. (2009) for a regional application. Later on, this E-tagging method has been implemented and verified with MM5 (Knoche and Kunstmann 2013) and WRF (Arnault et al. 2016a; InsuaCosta and Miguez-Macho 2018).
The E-tagging method developed by Arnault et al. (2016a) is used in this study. It has been incorporated in both standard WRF and coupled WRF-Hydro, and is compatible with the physics parameterizations selected for model setups in Sects. 3.1 and 3.2. The following tagging procedure is employed: (1) Define the upper HRB as the source region for water tracing, the evapotranspiration from the upper HRB (red outline in Fig. 1b) being labeled as the tagged evapotranspiration $\left(E T_{t a g}\right)$; (2) Analogously replicate the numerical formulations related to the advection and turbulent transport of the original water species $\left(q_{n}\right)$ for the tagged water species $\left(q_{n, t a g}\right)$; (3) Introduce a weighting coefficient $\left(q_{n, t a g}\right)$ $q_{n}$ ) for the computation of tagged water phase transitions. Following this procedure, tagged water species are traced until tagged precipitation at the surface $\left(P_{t a g}\right)$ or tagged advection outside of the domain's boundaries. It is noted that the tagged water species which leave the lateral boundaries of the model domain are set to zero, which means that the returning of tagged water species from outside of the domain is neglected.

\subsection{Quantitative measures of land-atmosphere interactions}

To quantify the interactions between land surface and atmosphere, we firstly use the analysis framework of land surfaceprecipitation feedback processes proposed by Schär et al. (1999) and advanced by Asharaf et al. (2012). This analysis is based on the atmospheric water balance, and assumes that the water vapor transported through a region and from the local evapotranspiration is well mixed.

For a control experiment, the relationship of precipitation $(\mathrm{P})$, evapotranspiration (ET), and the atmospheric water vapor transport in a specific region is described as:

$P=\chi\left(E T+Q_{\text {in }}\right)$.

$Q_{i n}$ is the atmospheric water inflow calculated by integration of water vapor fluxes through the boundary of the selected area. $\chi$ is called precipitation efficiency, which is

Table 1 List of the six WRF and WRF-Hydro experiments, along with the used PBL scheme, brief description of the PBL scheme, and the LSM parameterizations

\begin{tabular}{|c|c|c|c|}
\hline Experiment & PBL scheme & Short description of PBL & LSM \\
\hline WRFH-YSU & YSU & Nonlocal mixing; first-order closure; explicitly represent entrainment at the top of PBL & \multirow{3}{*}{$\begin{array}{l}\text { Hydrologically } \\
\text { enhanced Noah- } \\
\text { LSM }\end{array}$} \\
\hline WRFH-MYJ & MYJ & $\begin{array}{l}\text { Local mixing; use a 1.5-order closure scheme with a prognostic equation of turbulent } \\
\text { kinetic energy }\end{array}$ & \\
\hline WRFH-ACM2 & ACM2 & $\begin{array}{l}\text { Combination of local downward mixing and nonlocal upward convective mixing; first- } \\
\text { order closure }\end{array}$ & \\
\hline WRFS-YSU & YSU & Same as in WRFH-YSU & \multirow[t]{3}{*}{ Standard Noah-LSM } \\
\hline WRFS-MYJ & MYJ & Same as in WRFH-MYJ & \\
\hline WRFS-ACM2 & $\mathrm{ACM} 2$ & Same as in WRFH-ACM2 & \\
\hline
\end{tabular}


defined as the fraction of the water vapor entering a certain region, either by evapotranspiration or atmospheric water transport, that falls as precipitation within the same region afterward.

For a perturbation experiment, Eq. (1) can be rewritten as:

$P^{\prime}=\chi^{\prime}\left(E T^{\prime}+Q_{i n}^{\prime}\right)$,

where dashed variables stand for the conditions in the perturbation experiment. Subtracting Eq. (1) from Eq. (2), the precipitation difference $\Delta P$ is written as:

$\Delta P=P^{\prime}-P=\chi^{\prime}\left(E T^{\prime}+Q_{i n}^{\prime}\right)-\chi\left(E T+Q_{i n}\right)$,

where $\Delta$ denotes the differences between the perturbation experiment and control experiment. Rearranging the righthand terms according to Schär et al. (1999) and Asharaf et al. (2012), $\Delta P$ can be expressed as:

$\Delta P=\underbrace{\Delta \chi\left(\mathrm{ET}+Q_{\text {in }}\right)}_{\text {Efficiency } \text { effect }}+\underbrace{\chi \Delta \mathrm{ET}}_{\text {Surface effect }}+\underbrace{\chi \Delta Q_{\text {in }}}_{\text {Remote effect }}+\underbrace{\Delta \chi\left(\Delta \mathrm{ET}+\Delta Q_{\text {in }}\right)}_{\text {Residual }}$.

In Eq. (4), the precipitation difference $\Delta P$ is separated into three terms and residual. The first term reflects the processes affecting the transformation of available atmospheric water into precipitation. It is the indirect contribution through the changes in precipitation efficiency $\Delta \chi$, referred to as efficiency effect. The second and the third terms reflect the precipitation change by direct contribution through the changes in surface evapotranspiration $\triangle E T$ and changes in atmospheric water vapor inflow $\Delta Q_{i n}$, referred to as surface effect and remote effect, respectively. The residual term is very small and can be neglected. Therefore, this analysis allows distinguishing between the direct and indirect processes of lateral terrestrial flow on the simulated precipitation from the model simulations. In this study, the coupled WRF-Hydro ensemble is considered as the perturbation experiment which additionally depicts the lateral terrestrial flow. The feedback analysis based on Eq. (4) is conducted with WRF and coupled WRF-Hydro simulations which use the same PBL scheme (blue line in Fig. S1).

Precipitation recycling ratio is used as another measure for quantifying land surface-atmosphere interactions strength. Precipitation recycling ratio is defined as the fraction of evaporation-originated precipitation in the total precipitation, in this case for the upper HRB area. Based on the E-tagging method, the precipitation recycling ratio is calculated as:

$\beta=P_{\text {tag }} / P$.

The higher value of $\beta$ stands for a higher contribution of locally evaporated water to local precipitation.

\section{Results and discussion}

The quantification measures of land-atmosphere interactions depend on the performance of modeling results in reproducing the hydrometeorological fields, i.e., precipitation, temperature, evapotranspiration, and discharge. Therefore, the simulated hydrometeorological fields from model ensembles are evaluated and discussed at first, then followed by discussions on quantified land-atmosphere interactions.

\subsection{Hydrometeorological fields}

\subsubsection{Precipitation}

The annual precipitation from model ensembles is spatially compared with the CMFD gridded precipitation and ground measurements in Fig. 2. As illustrated in Fig. 2a, the observational reference shows a precipitation band along with the Qilian Mountain, with a decrease of precipitation from southeast to the northwest. The heavy precipitation is centered to the south of HRB, while the minimal precipitation is spread over the lowland area in the north. All the considered ensemble members capture the above spatial pattern of precipitation, and are consistent with the ground measurements (Fig. 2b-f). The monthly averaged precipitation in the upper HRB from Hydro-ensembles WRFS and WRFH, is temporally compared with CMFD in Fig. 3a. It shows that all the simulations skillfully reproduce the monthly and seasonal variation of precipitation. Similar to many RCM simulations (e.g., Pan et al. 2014; Xiong and Yan 2013; Yang et al. 2017b; Zhang et al. 2018), all the model ensembles overestimate precipitation over the high mountains from May to August (Fig. 3a). In comparison to CMFD precipitation for the upper HRB, the Hydro-ensembles WRFS and WRFH overestimate precipitation by $221 \mathrm{~mm} /$ year and $231 \mathrm{~mm} /$ year respectively, and the PBL-ensembles simulate 201-254 mm/year more precipitation, in which the ACM2 ensemble shows the smallest bias and MYJ ensemble shows the highest. Taking into account the fact that CMFD merges sparse ground observations over flat valley area around the study area (Fig. 1b), the wet bias of precipitation in the upper HRB could be partially attributed to the fact that high mountain precipitation is not well represented in the gridded reference dataset (Chen et al. 2015; Pan et al. 2014; Yang et al. 2017b).

Spatially, all the WRF and coupled WRF-Hydro experiments show much more spatial details in comparison to the reference data, in relation to the high resolution employed for the simulation. In the high mountains to the south, 

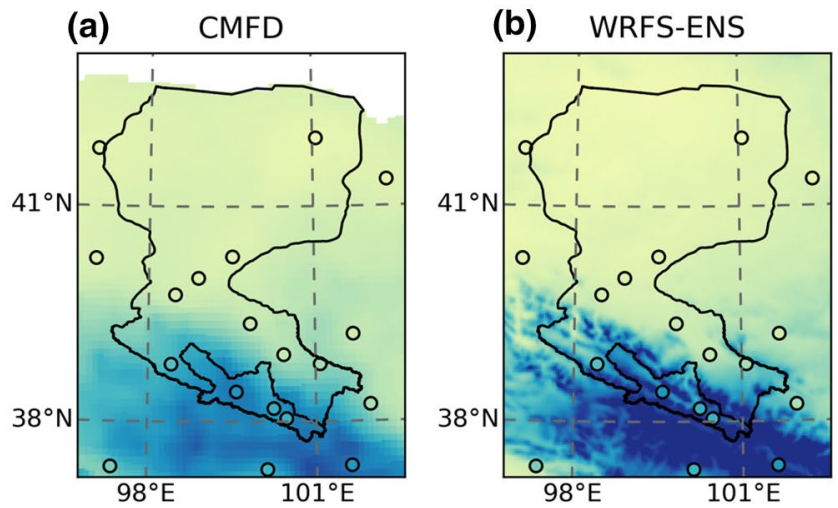

\section{(c) WRFH-ENS}
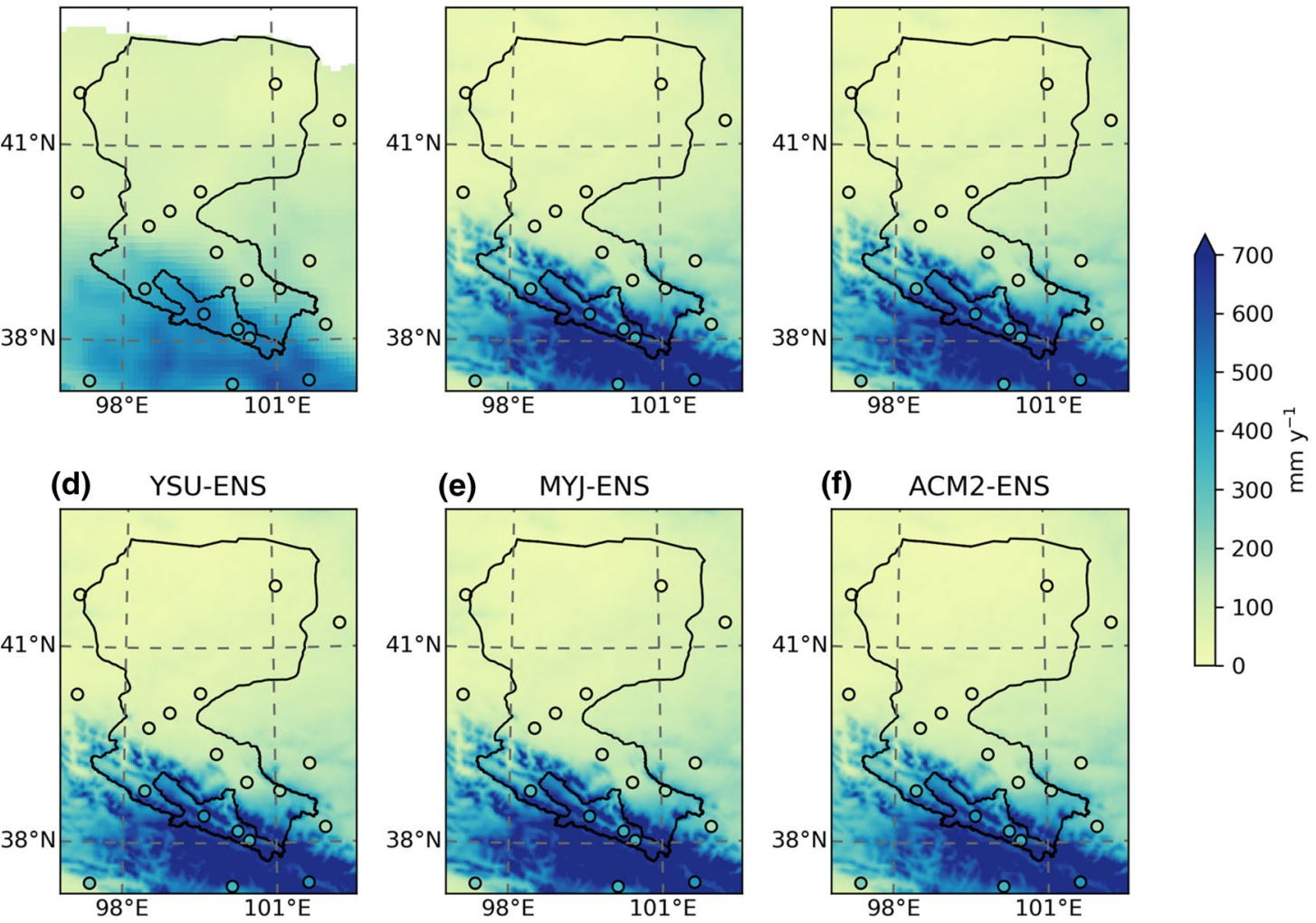

Fig. 2 Annual accumulated precipitation derived from a CMFD, and the Hydro-ensembles of $\mathbf{b}$ WRFS-ENS and $\mathbf{c}$ WRFH-ENS for the period 2008-2010. d-f are for the PBL-ensembles of d YSU-ENS, e
MYJ-ENS and f ACM2-ENS. Colored circles represent the groundobserved precipitation from in-situ stations

with a spatial correlation of 0.96 for the whole HRB and 0.81 for the upper HRB. Comparing with CMFD reference, the simulated near-surface temperature from all ensemble members is slightly lower during the summertime and higher during the wintertime (Fig. 3b), with a warm bias ranging from 0.3 to $0.9^{\circ} \mathrm{C}$. This model performance is fairly comparable to that obtained with other RCM simulations (e.g., Gao et al. 2015; Pan et al. 2012).

\subsubsection{Evapotranspiration and soil moisture}

Evapotranspiration (ET) and surface soil water content from the Hydro-ensembles are evaluated with the GLEAM and ESA CCI datasets as time series for the upper HRB in Fig. 3c, d. Soil water content comparison is only available during summertime due to the general missing values in the wintertime. In general, simulated monthly ET in the upper HRB shows good agreement with GLEAM with correlation coefficients above $0.84(\mathrm{p}<0.01)$ and the simulated soil water content is also quite comparable with ESA CCI observations. Overall, the Hydro-ensemble WRFH overestimates ET by about $61 \mathrm{~mm} /$ year while WRFS underestimates ET by about $11 \mathrm{~mm} /$ year. As shown in Fig. 3c, d, 
Fig. 3 Monthly variation of a precipitation, b 2-m air temperature, $\mathbf{c}$ evapotranspiration and d soil water content averaged in the upper HRB from reference datasets (CMFD, GLEAM, ESA CCI), and the Hydro-ensemble (WRFS-ENS, WRFH-ENS) in the period of 2008-2010 (a)

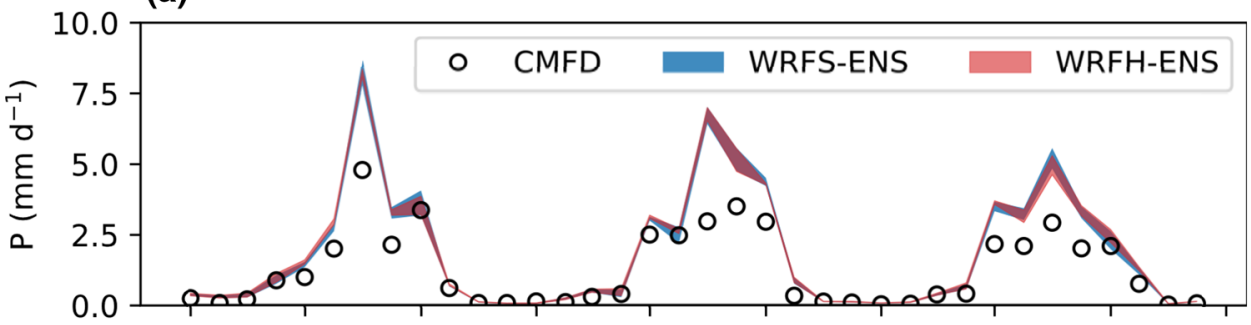

(b)

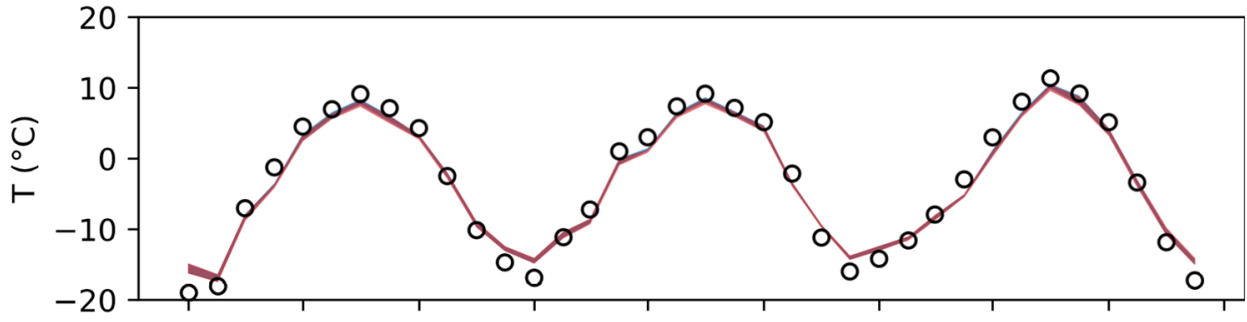

(c)

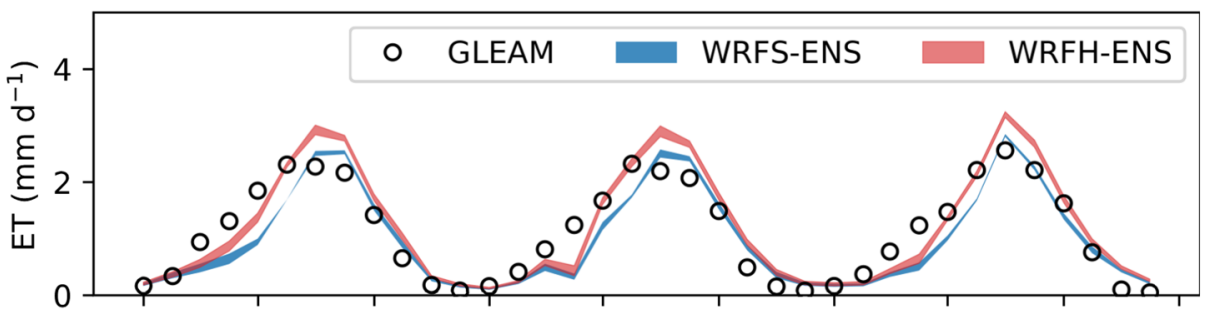

(d)

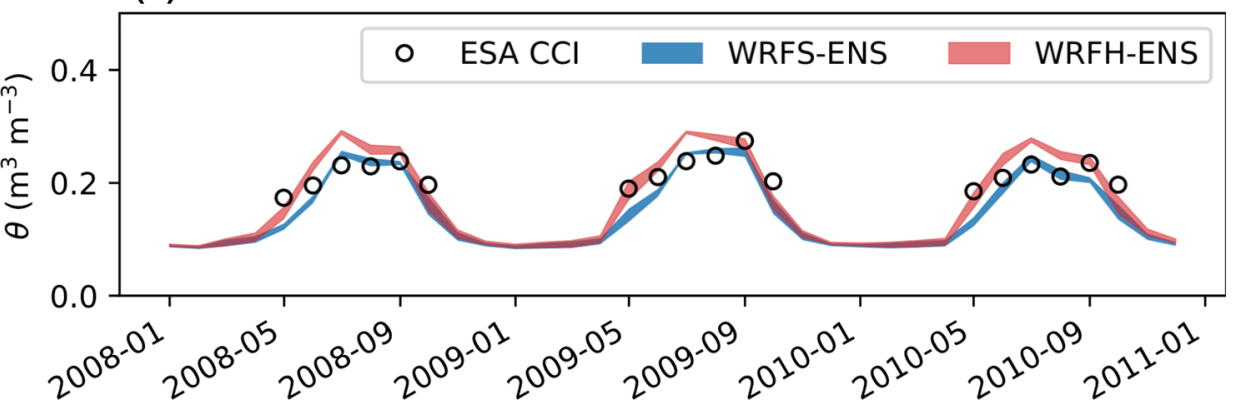

WRFH overestimates the peak value of ET in the summertime, which is associated with the higher soil moisture in the WRFH ensemble. All simulations slightly underestimate ET during March and April in the upper HRB where elevation is high. As the air temperature is below $0{ }^{\circ} \mathrm{C}$ (Fig. 3b) and the precipitation is low (Fig. 3a) during this springtime, the underestimated ET could be largely attributed to an inaccurate specification of the frozen soil thawing mechanism in land surface modeling (Duan et al. 2018; Zhang et al. 2019; Zheng et al. 2017). In Fig. 5, the spatial pattern of ET in GLEAM is fairly represented in the model ensembles, with a maximum in the southeast, and declining values from the southern to the northern HRB. It is noted that simulation results additionally represent spatial variations of ET according to local vegetation conditions and precipitation distribution (Fig. 2). These high-resolution features of ET, which cannot be detected in the GLEAM dataset, are similar to those shown by satellite data-derived results $(\mathrm{Wu}$ et al. 2020).

\subsubsection{Impact of lateral terrestrial flow on hydrometeorological fields}

The role of lateral terrestrial flow on simulated hydrometeorological variables is inspected by intercomparing the Hydro-ensembles WRFH and WRFS (Sect. 3.2). Displayed 

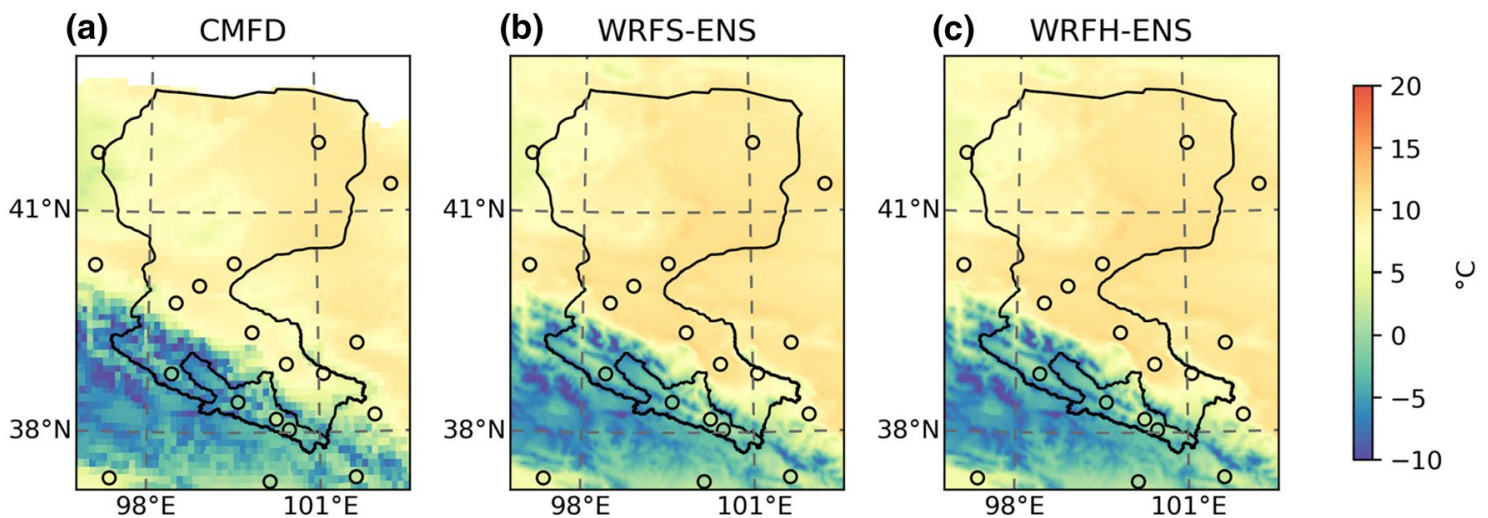

Fig. 4 Annual mean 2-m air temperature derived from a CMFD, and the Hydro-ensemble of $\mathbf{b}$ WRFS-ENS and $\mathbf{c}$ WRFH-ENS for the period 2008-2010. Colored circles represent the ground-observed 2-m air temperature from in-situ stations
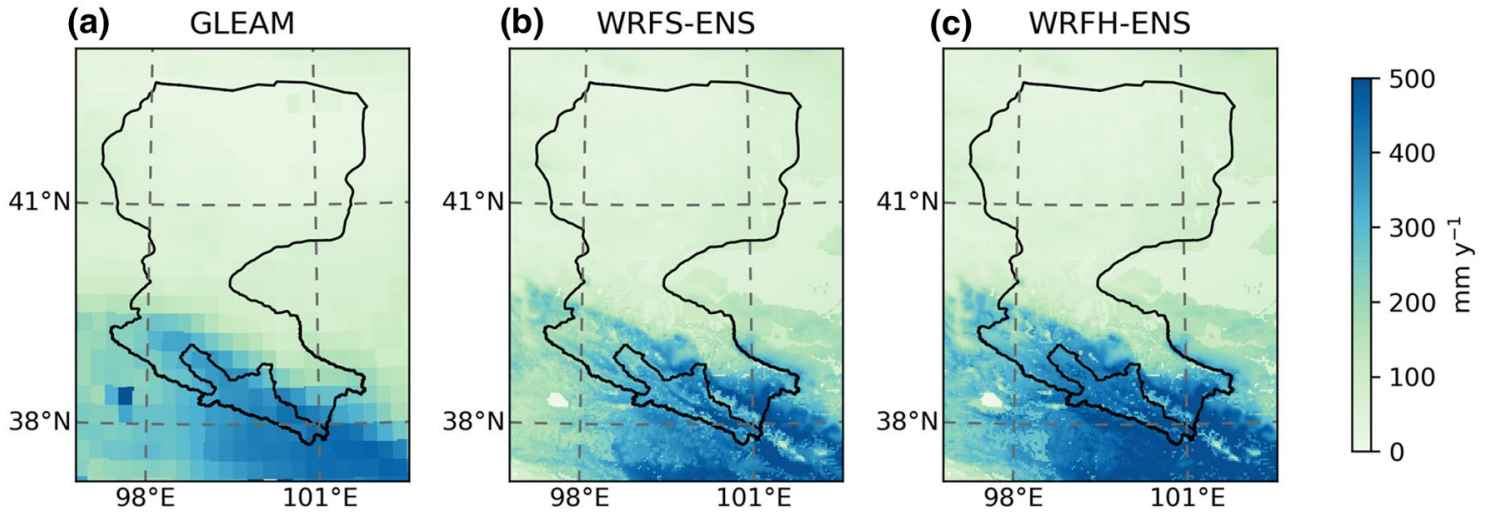

Fig. 5 Annual mean accumulated evapotranspiration derived from a GLEAM, and the Hydro-ensembles of $\mathbf{b}$ WRFS-ENS and $\mathbf{c}$ WRFH-ENS for the period 2008-2010

in Fig. 3, the monthly time series of precipitation from the two Hydro-ensembles show similar variations, with small differences in the monthly amounts, while the ET and soil moisture is distinctly higher in WRFH, with around $0.5 \mathrm{~mm} /$ day more ET and $0.03 \mathrm{~m}^{3} / \mathrm{m}^{3}$ higher soil water content than those in WRFS during the summertime. Furthermore, the range of ET in each Hydro-ensemble is generally less than $0.18 \mathrm{~mm} /$ day (Fig. 3c). This robustly indicates that the increase of evapotranspiration in WRFH corresponds to the description of lateral terrestrial flow, regardless of the precipitation uncertainties. Since lateral flow does not directly affect the snowpack, the snow melting process is related to the simulated air temperature, which is comparably similar in all ensemble simulations (Fig. 3b). Slight differences in snowmelt are associated with the differences in snowfall between WRFS and WRFH ensembles (Fig. S3).

The spatial differences of related hydrometeorological variables are explored for the months from May to
September (Fig. 6), which is defined as the rainy-season (Su et al. 2017; Zhang et al. 2018). By enabling lateral terrestrial hydrological processes within atmosphere modeling, the land surface in turn is affected according to the terrain complexity. Regardless of the precipitation differences, Fig. 6c shows that ET systematically increased over the areas with high elevation gradients in the Qilian Mountains, and with small differences in the northern flat regions and flat valleys. The increase of ET is consistent with the increase of soil moisture, which is caused by laterally moved and re-infiltrated surface runoff. Temperatures between the two Hydro-ensembles are rather similar. WRFH shows slightly lower near-surface temperature than WRFS alongside the mountains, within $-0.2{ }^{\circ} \mathrm{C}$, as a consequence of a more evaporative cooling effect. These wetting and cooling results in mountainous areas are consistent with findings in the Eastern Alps area (Rummler et al. 2019). 
Fig. 6 Differences in a accumulated precipitation, $\mathbf{b}$ mean $2-\mathrm{m}$ air temperature, $\mathbf{c}$ accumulated evapotranspiration, and $\mathbf{d}$ surface soil moisture between the Hydro-ensembles (WRFHENS minus WRFS-ENS) for the rainy-season (May-September) in 2008-2010
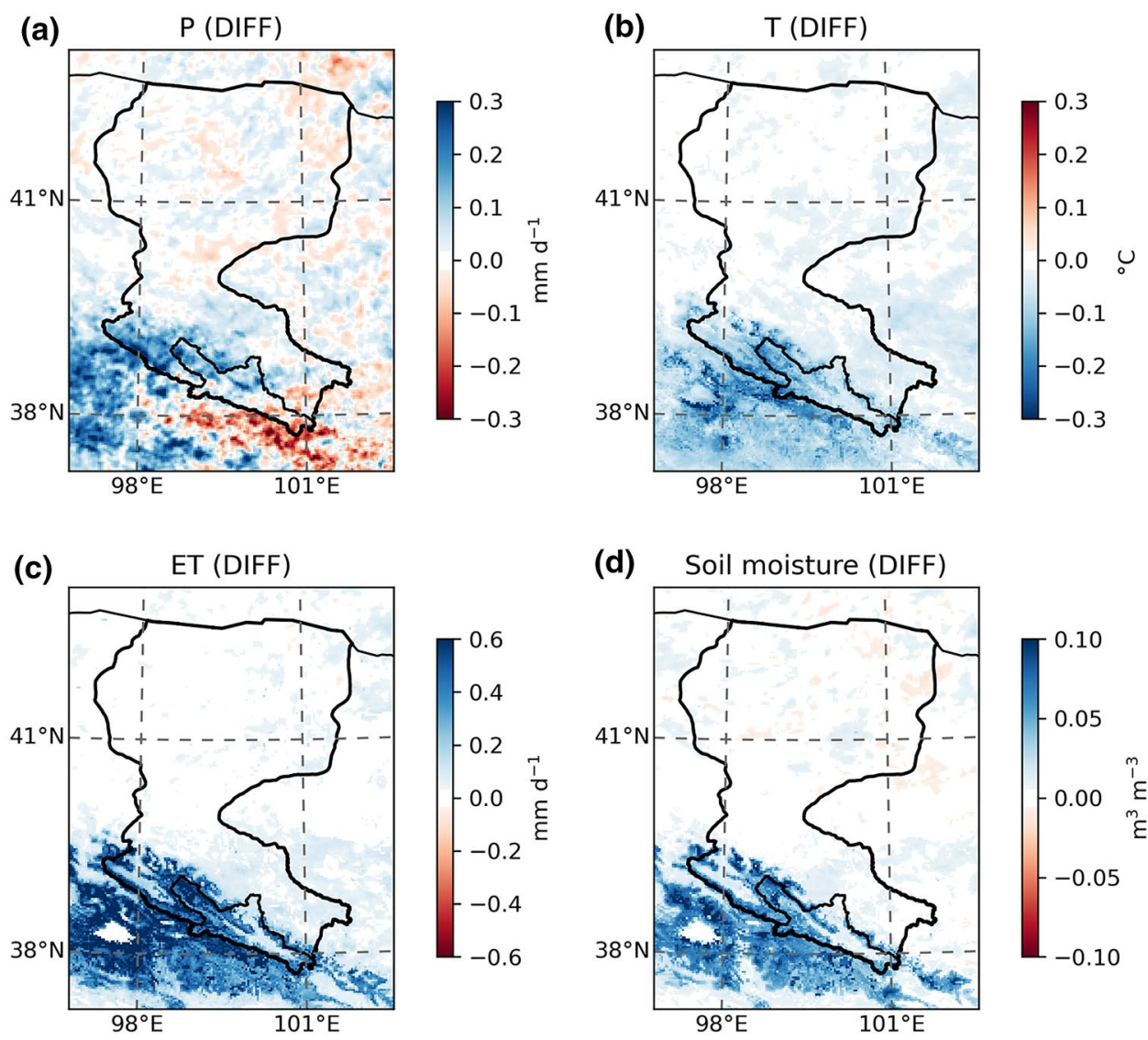

\subsection{Streamflow}

Simulated streamflow hydrographs from the coupled WRFHydro ensemble are compared with gauge observations in Fig. 7. In general, the timing of hydrograph peaks and the flow recession are well captured by all ensemble members. The temporal variations of streamflow are comparable with observed streamflow, except for the baseflow amount during the dry period, which is mostly underestimated. Apart from the fact that WRF-Hydro explicitly describes the subsurface flow in a soil layer of $2 \mathrm{~m}$ depth only and oversimplifies deeper groundwater processes with a simple bucket baseflow parameterization (Gochis et al. 2015; Li et al. 2017; Rummler et al. 2019; Yucel et al. 2015), streamflow underestimation during low flow period could be further attributed to a lack of glacier wastage modeling in the current model framework.

As indicated in previous coupled WRF-Hydro applications (Arnault et al. 2016b; Kerandi et al. 2018; Rummler et al. 2019; Senatore et al. 2015), our results similarly underline the impact of simulated precipitation on streamflow simulation. Related to the overrated precipitation amount, the peak flows are mostly overestimated during the rainyseason, resulting in low KGE coefficient values spanning from 0.02 to 0.21 . With respect to different PBL schemes used in the coupled modeling, the simulated hydrographs in all members are similar, however, distinguishable ranges are obtained at flow peaks during the rainy period. This behavior is quite comparable to the ensemble simulations over central Europe and Alps catchments (Arnault et al. 2018; Rummler et al. 2019). The uncertainties in the peak flows can be justified by the simulated precipitation differences, which not only rely on the amounts and spatial distributions, but also on the intensity and duration of heavy precipitation events (Kokkonen et al. 2004; Rasmussen et al. 2012). Nevertheless, the ratios of total streamflow to precipitation are reasonably reproduced at all three gauges. The calculated streamflow ratios show values of $0.38-0.40$ at Qilian gauge, $0.40-0.41$ at Zhamashike gauge, and $0.36-0.38$ at Yingluoxia gauge, respectively, and these are quite comparable with various pure hydrological modeling results (Chen et al. 2018b; Gao et al. 2016; Li et al. 2018b; Ruan et al. 2017; Yang et al. 2015).

\subsection{Land surface-precipitation feedback processes}

As the precipitation amount during the dry season is quite small and similar among all ensemble members (Fig. 3a), the land surface-precipitation feedback analysis focuses on the rainy-season from May to September. Figure 8 
Fig. 7 Range of daily time series of simulated streamflow by the coupled WRF-Hydro ensemble at the outlets of the gauges a Yingluoxia, b Qilian and $\mathbf{c}$ Zhamashike for the period 2008-2009. The observed streamflow is shown as black solid lines

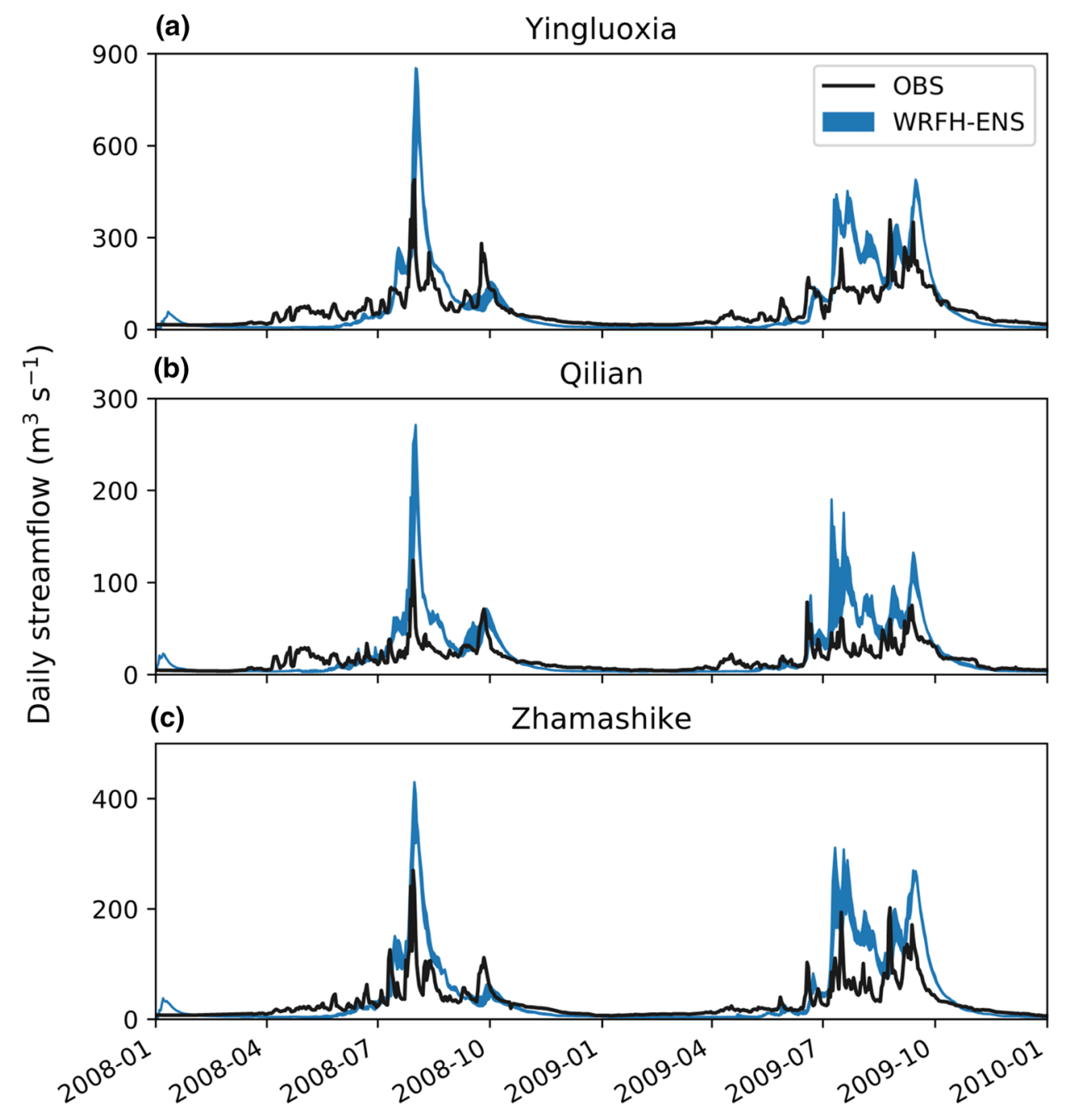

displays the quantified effect terms of lateral terrestrial flow on precipitation in the upper HRB with each PBL scheme. The results among different PBL schemes are quite consistent. The direct contribution of evapotranspiration changes to precipitation changes is small and positive in all months, in relation to the higher evapotranspiration in coupled WRF-Hydro. Since the soil moisture conditions can modify mesoscale moisture convergence thereby affect atmospheric water inflow (e.g., Cook et al. 2006; Koster et al. 2016; Schär et al. 1999), the remote effect reaches its maximum value in July when the water transport is the strongest. The positive or negative remote effects are related to the atmospheric moisture convergence differences and the relative location of the study area (Fig. S5j-1). The efficiency effect shows the dominant contribution to the change of precipitation, with the largest absolute value throughout the rainy-season. In the model system, this efficiency effect corresponds to the convection organization triggered by moisture convergence and model physical processes. Being influenced by lateral terrestrial flow, the modeled specific humidity and latent heating (i.e., evapotranspiration) increase at the land surface (Fig. $\mathrm{S} 4 \mathrm{j}-1$ ), in association with a shallower boundary layer, a decrease in lifting condensation level, and an increase of most unstable convective available potential energy across southern mountains (Fig. S5a-j). These results suggest that the lateral terrestrial flow potentially affects the spatial distribution and strength of convection through a change in atmosphere stability, similar to the study cases of direct perturbation of wetter soil moisture conditions (e.g., Asharaf et al. 2012; Froidevaux et al. 2014; Wei et al. 2016). Therefore, although the lateral terrestrial flow has a relatively small direct impact on precipitation, it promotes much larger indirect impact on precipitation through atmospheric moisture convergence and convective processes.

As atmospheric moisture convergence and convection formation are both influenced by model physical parameterization schemes, the precipitation changes and the quantified effects are varying from month to month among three 
Fig. 8 Monthly quantified change of precipitation (WRFHPBL minus WRFS-PBL) in the upper HRB for the rainy-season in 2008-2010

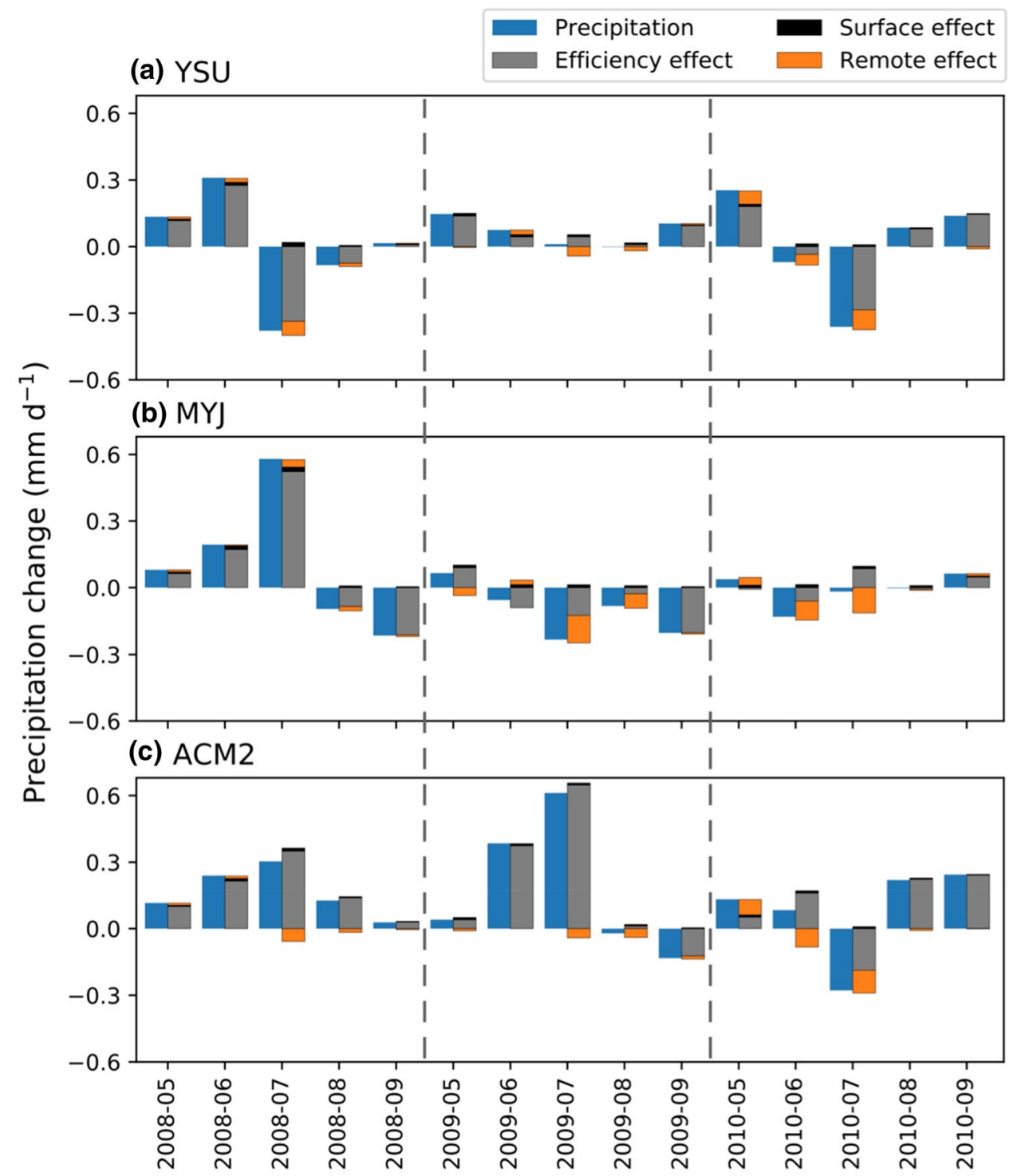

PBL-ensembles. The effect of different PBL schemes will be investigated using E-tagging method in the following section.

\subsection{Evapotranspiration tagging and precipitation recycling}

\subsubsection{Distribution of tagged precipitation and precipitation recycling}

The tagged evaporated water which precipitates at the ground, namely the tagged precipitation $\left(\mathrm{P}_{\text {tag }}\right)$, and the precipitation recycling ratio are spatially displayed in Fig. 9 for the standard WRF simulations with the three PBL schemes. The results from coupled WRF-Hydro simulations are similar and are displayed in Figure S6. The tagged precipitation is mainly distributed around the source region, the upper
$\mathrm{HRB}$, and alongside the mountain range stretching from southeast to northwest. Besides, the higher amount of tagged precipitation falls at the mountain peaks within and to the south of the upper HRB, which confirms the role of the Qilian Mountain blocking the atmospheric water transport to the Tibet Plateau (Li et al. 2015; Wang et al. 2018b).

Only a small portion of evaporated water falls back to the source area, resulting in an annual precipitation recycling ratio less than $2.2 \%$ (Table 2), whereas the predominant portion flows outside the domain boundaries. In Fig. 10, the calculated monthly precipitation recycling ratio ranges from 0.05 to $3.9 \%$, which is comparable to that obtained in a previous study (Zhang et al. 2019). This low precipitation recycling feature in the study area is confirmed by all ensemble members, and it is mainly related to the fact that the source area is small. The precipitation recycling ratio is scale-dependent, explaining that it tends to zero at the 

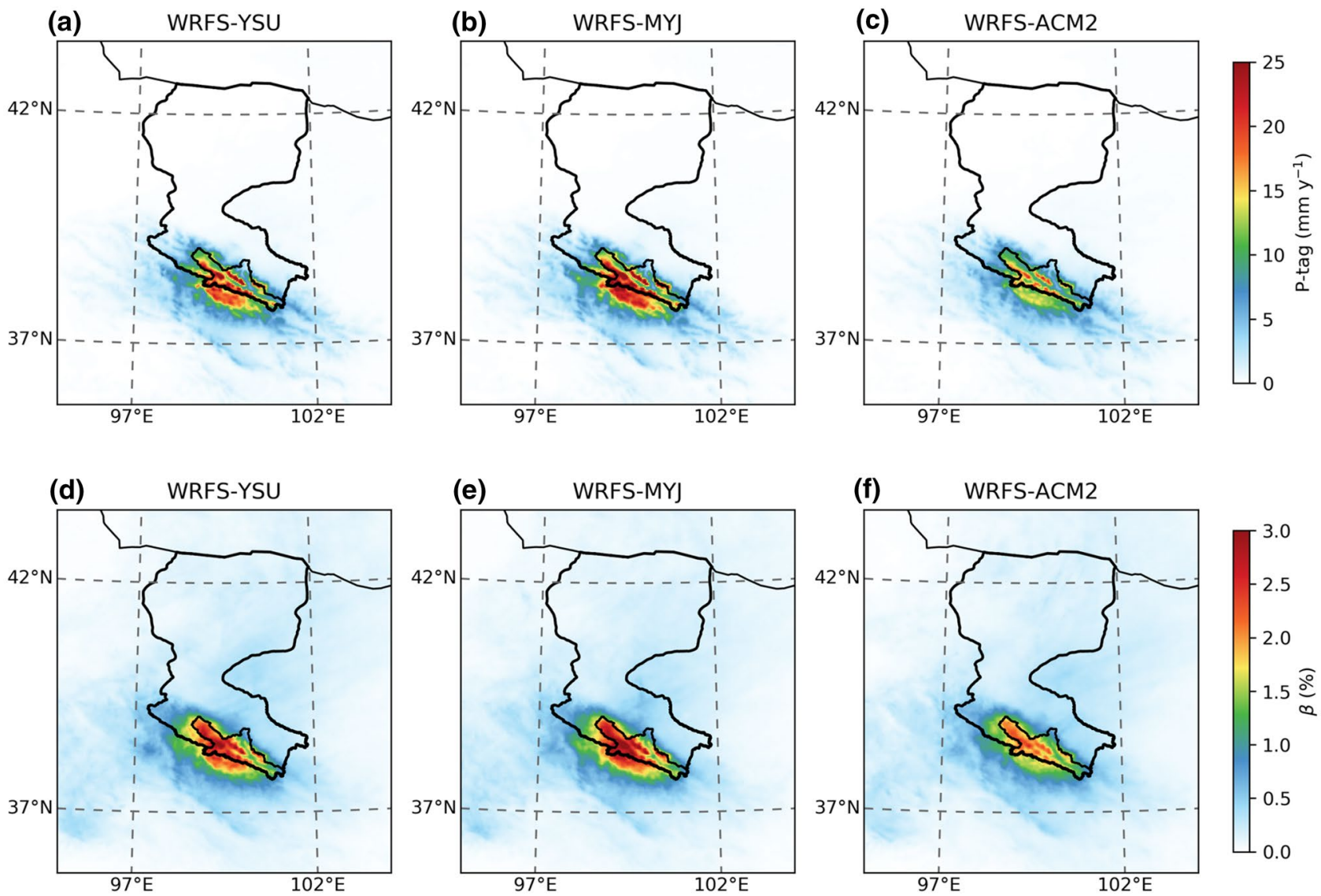

Fig. 9 Spatial pattern of $\mathbf{a}-\mathbf{c}$ annual tagged precipitation amount and precipitation recycling $\mathbf{d}-\mathbf{f}$ from the WRF standalone simulations (WRFS) with respect to 3 PBL schemes for the period 2008-2010

Table 2 Annual precipitation recycling of the upper HRB for each model ensemble member

\begin{tabular}{lll}
\hline PBL scheme & WRFS- $(\%)$ & WRFH- (\%) \\
\hline YSU & 1.53 & 1.90 \\
MYJ & 1.76 & 2.19 \\
ACM2 & 1.28 & 1.61 \\
\hline
\end{tabular}

point-scale and reaches 1 at the global-scale (Arnault et al. 2016a; Burde and Zangvil 2001; Trenberth 1999). In the following, we compare the E-tagging results among ensemble members to investigate the PBL-related and lateral terrestrial flow-induced changes in local recycled precipitation.

\subsubsection{Impact of PBL scheme on precipitation recycling}

As shown in Figs. 9, S6 and Table 2, it is found that the annual tagged precipitation and precipitation recycling show differences among the PBL schemes. For the WRFS ensemble, the MYJ scheme has the largest amount of tagged precipitation around $15.5 \mathrm{~mm} /$ year, and the highest precipitation recycling ratio of $1.76 \%$. The ACM2 scheme has the lowest amount of tagged precipitation of $11.9 \mathrm{~mm} /$ year, with a precipitation recycling ratio of $1.28 \%$. A similar difference among the PBL schemes is also found in the case of the WRFH ensemble (Table 2).

The calculated monthly precipitation recycling ratios for all ensemble members are displayed in Fig. 10. The precipitation recycling ratio shows a distinct seasonal cycle, which is quite comparable among all PBL schemes, showing the lowest values during the winter season and higher values in the summer season. For the magnitude, again, the highest precipitation recycling ratio is found in the PBL scheme of MYJ throughout the whole period, and the ACM2 scheme shows the lowest values. These differences in precipitation recycling could be explained by the local closure difference in the PBL parameterization. The local closure schemes (i.e., MYJ) usually produce insufficient mixing in the convective boundary layer (Brown 1996; Cohen et al. 2015; Xie et al. 2012), and this weaker vertical mixing tends to transfer less surface water vapor to higher atmospheric levels (Hu et al. 2010). However, the nonlocal schemes (i.e., YSU, ACM2) usually 
Fig. 10 Monthly precipitation recycling ratio calculated from all WRF standalone and coupled WRF-Hydro ensemble members

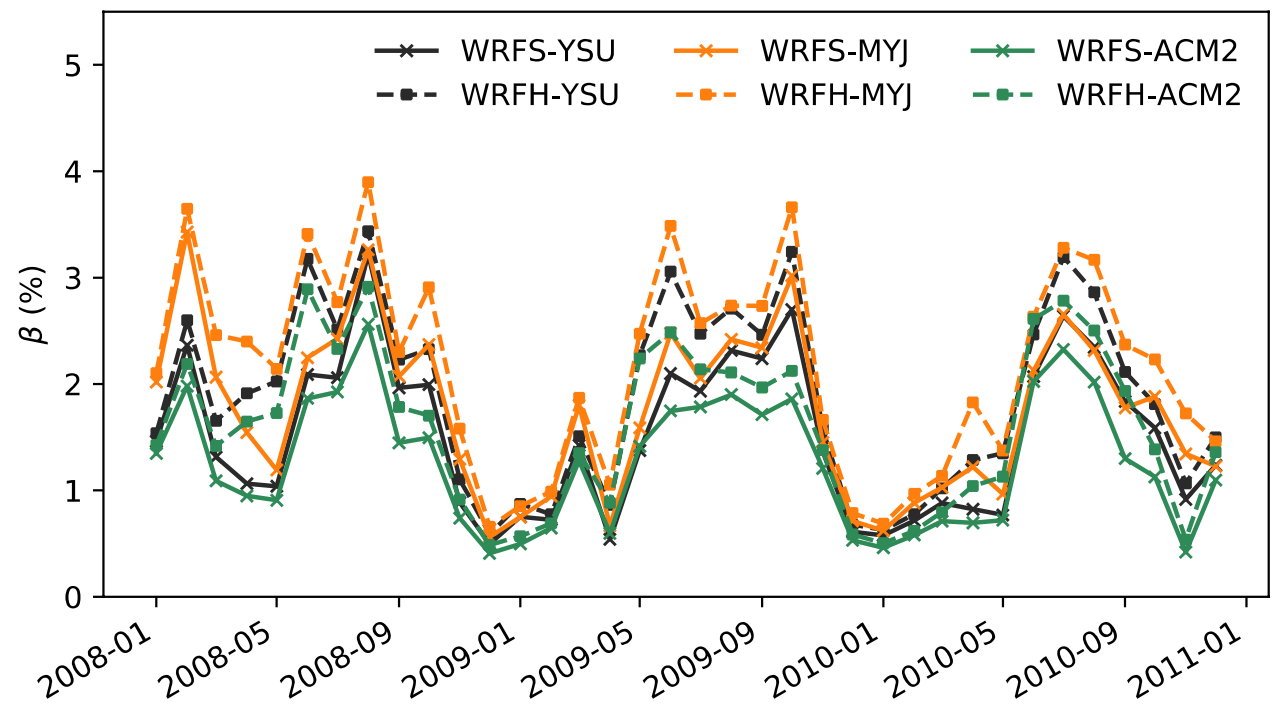

transport more moisture away from the surface and deposit more moisture at a higher atmospheric level (Hong and Pan 1996; Hu et al. 2010; Srinivas et al. 2007). These differences in moisture mixing are exemplified in the vertical profile shown in Fig. 11. The MYJ scheme exhibits more moisture in the low atmosphere below the height of $5500 \mathrm{~m}$, whereas the ACM2 scheme displays the lowest moisture. In the higher atmosphere, the ACM2 scheme is inversely showing the higher moisture mixing ratio with respect to the YSU and MYJ schemes. As the moisture particles in the higher atmosphere levels can be transported farther away to remote regions, the precipitation recycling ratio from the ACM2 scheme is accordingly low.

\subsubsection{Impact of lateral terrestrial flow on precipitation recycling}

Figures 12 and 13 illustrate the precipitation recycling differences between the Hydro-ensemble WRFH and WRFS as spatial maps and monthly time series, respectively. Concerning the impact of lateral terrestrial flow, spatial precipitation recycling increases in the northwestern upper $\mathrm{HRB}$, with a total increased ratio of $0.47 \%$ and up to $0.93 \%$ in mountain peaks (Fig. 12). Despite the uncertainties introduced by the PBL schemes, lateral terrestrial flow systematically increases the monthly precipitation recycling ratios, up to $1.2 \%$ more in the summertime (Fig. 13). (a)

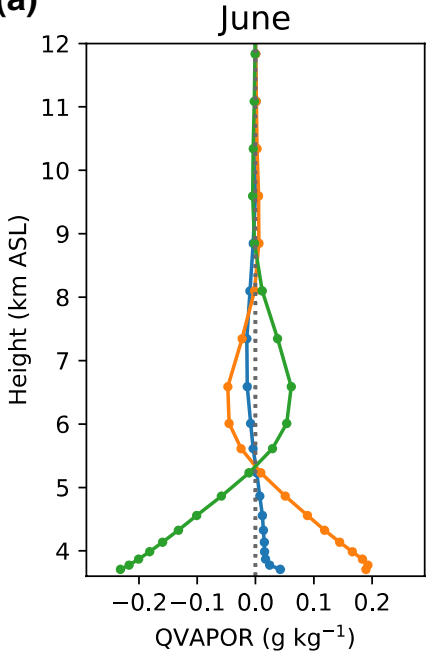

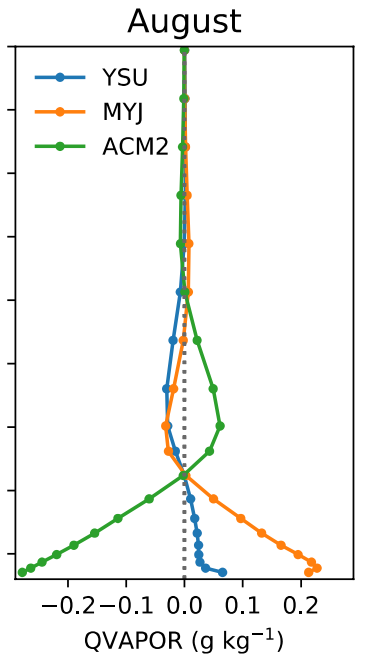

(b)

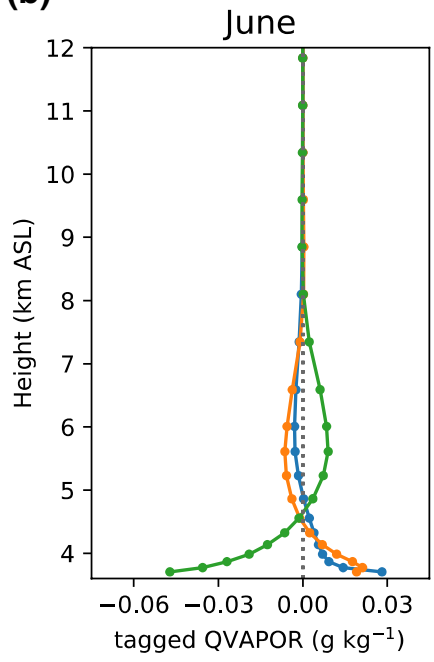

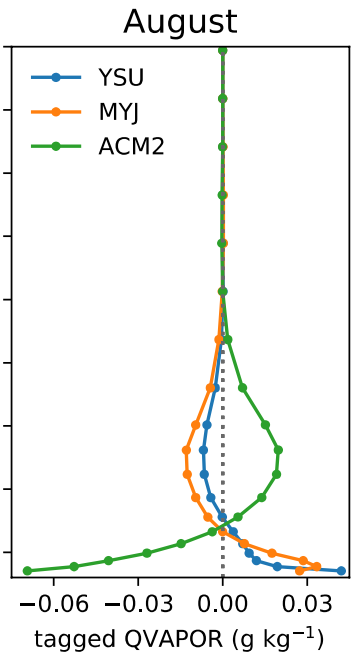

Fig. 11 Vertical profiles of the difference in $\mathbf{a}$ total water vapor mixing ratio and $\mathbf{b}$ tagged water vapor mixing ratio between three PBL parameterization schemes for June and August in 2008. Differences are respectively calculated from each PBL ensemble and their ensemble mean 
Differential vertical profiles of moisture mixing ratio between the WRFH and WRFS are shown in Fig. 14, one for June 2008 when the recycling ratio differences is the largest, and the other for August 2008 when the differences display the widest range. For both months, WRFH enhances the moisture in the lower atmosphere and decreases moisture in the higher atmosphere up to the height of $9000 \mathrm{~m}$. The tagged moisture in WRFH is comparatively higher below the
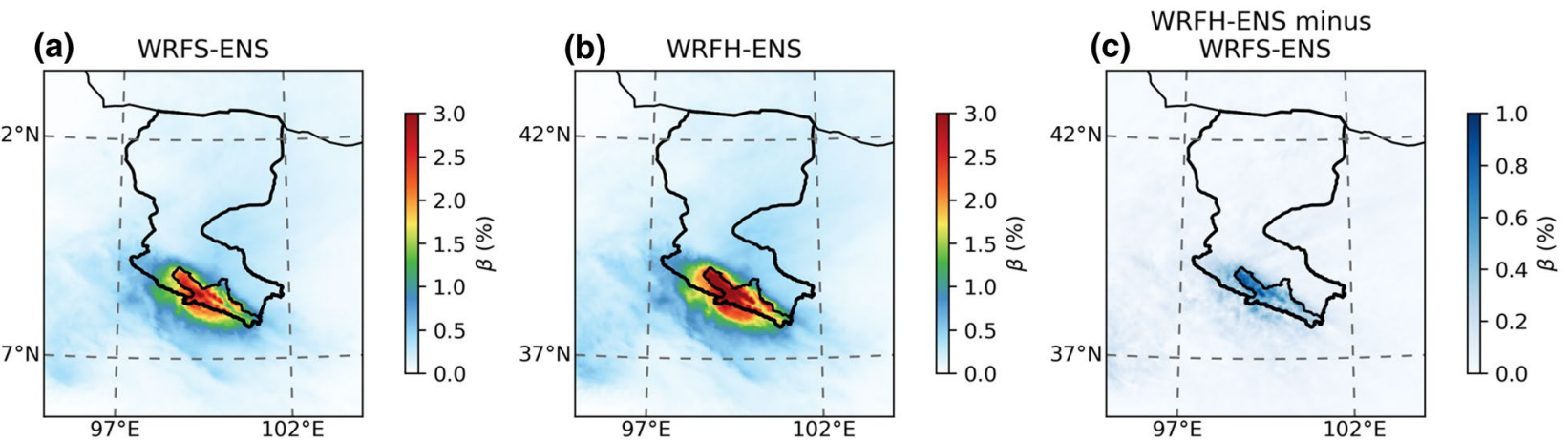

Fig. 12 Spatial pattern of precipitation recycling from Hydro-ensembles of a WRFS, $\mathbf{b}$ WRFH and $\mathbf{c}$ their difference (WRFH minus WRFS)

Fig. 13 Monthly precipitation recycling ratio differences with respect to lateral terrestrial flow. Differences are respectively calculated from WRFH- and WRFS- for each PBL scheme

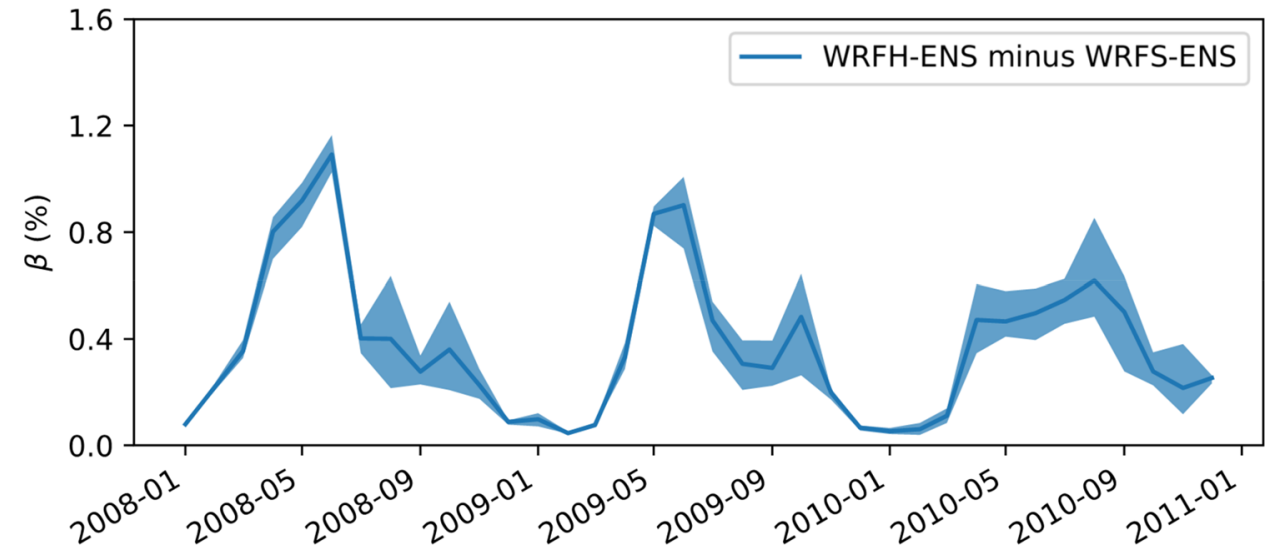

(a)

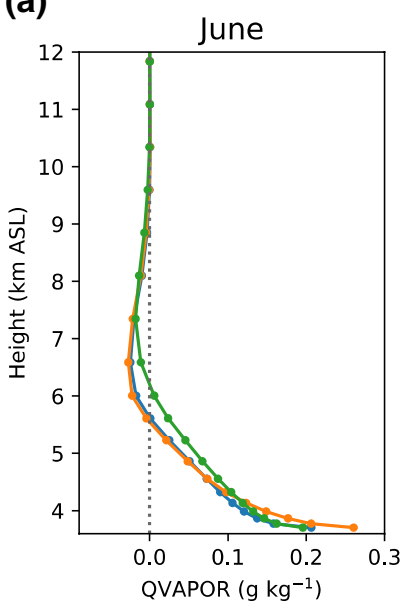

August

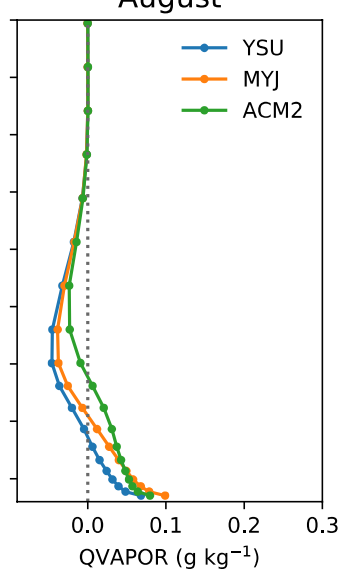

(b)

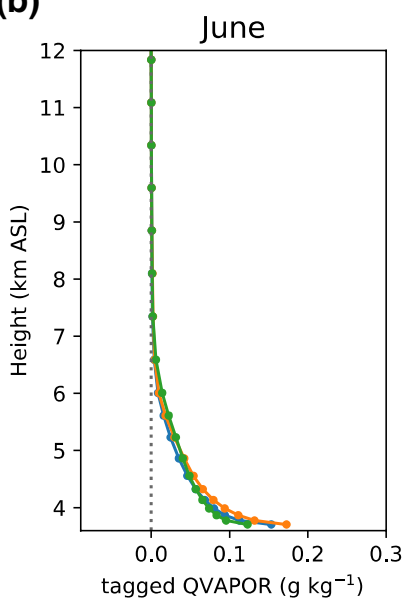

August

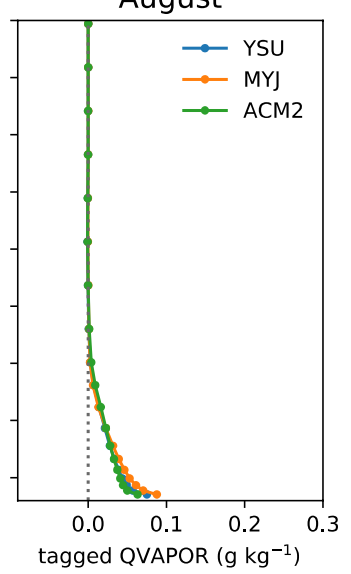

Fig. 14 Vertical profiles of the differences in a total water vapor mixing ratio and $\mathbf{b}$ tagged water vapor mixing ratio between WRFH- and WRFfor June and August in 2008. Differences are respectively calculated from WRFH- and WRFS- for each PBL scheme 
height of $7000 \mathrm{~m}$. The vertical change of moisture mixing ratio robustly illustrates that the enriched evapotranspiration in WRFH intensifies the wetting in the lower atmosphere and reduces the mixing ratio in the free convection level above. This lateral terrestrial flow-induced feedback mechanism is comparable to the results of positive feedbacks obtained by directly perturbating soil moisture fields to a wetter condition (Schär et al. 1999). As such an intensified wetting in the low atmosphere causes convective instability and increases the possibility of moist convection (Derbyshire et al. 2004; Yin et al. 2015), thereby increasing the local precipitation recycling. However, as shown in Figs. 6a and 8, the increase of precipitation recycling ratio is not necessarily associated with an increase of precipitation, as the precipitation in the study area is dominated by remote water sources through atmospheric water transport. In particular, this ensemble result confirms the blocking effect of topography in the weakened East Asian summer monsoon environment, and endorses the positive feedback of local land-atmosphere interactions in the study area.

\section{Summary and conclusions}

In this study, we have addressed the sensitivity of simulated land-atmosphere interactions to model physics parameterization and lateral terrestrial flow description over a high mountainous area, the Heihe River Basin in Northwest China. Two ensembles of convection-permitting simulations with the fully coupled atmosphere-hydrology model WRFHydro and the standalone WRF model are generated by varying turbulence parameterization with three PBL schemes (YSU, MYJ, and ACM2), which allows for assessing the robustness of results. All the simulations are set up for three consecutive years from 2008 to 2010, using 3-km high horizontal resolution. To assess the strength of land-atmosphere interactions, the advanced evaporated water tagging method is embedded with both WRF-Hydro and WRF to quantify the contribution of local evaporated water to precipitation in the study area. Our main findings are summarized in the following.

Ensemble results show that spatial patterns and monthly variations of air temperature, precipitation, and evapotranspiration are similarly simulated by changing the PBL scheme and terrestrial flow description. PBL schemes show a modest impact on the simulated monthly basin-averaged precipitation and evapotranspiration. By considering lateral terrestrial flow movement in coupled WRF-Hydro, evapotranspiration is distinctly increased with surface soil moisture regardless of different PBL parameterization, whereas the precipitation is not much affected.

Driven by atmospheric lateral boundary forcing only, the coupled WRF-Hydro ensemble reasonably reproduces the daily streamflow in its seasonal cycle and variabilities. Different PBL parameterizations induce a spread in simulated streamflow during the rainy and peak flow period, but not during the dry and recession period. This highlights the sensitivity of simulated streamflow to modeled precipitation in fully coupled modeling.

The results of land surface-precipitation feedback analysis and evaporated water tagging demonstrate the positive feedback and the non-neglectable role of lateral terrestrial flow on land-atmosphere interactions in the study area. Despite the relatively small precipitation recycling values less than $2.2 \%$, which is related to the small-scale analysis area, PBL parameterization and lateral terrestrial flow are found to both affect the regional precipitation recycling. A reduced vertical mixing is associated with a higher precipitation recycling.

Overall, this joint investigation demonstrates the simulated land-atmosphere interactions strength in dependency of the parameterized model physics in regional climate modeling. Most importantly, the presented ensemble results highlight that the precipitation recycling ratio increases spatially and temporally due to the consideration of the lateral water flow, irrespective of how the PBL scheme parameterizes vertical mixing. This result reinforces the noteworthy role of lateral terrestrial flow components in the modeled hydrology-land surface-atmosphere earth systems (e.g., Fan et al. 2019; Prein et al. 2015; Santanello et al. 2018). We conclude that further studies targeting land-atmosphere interactions by applying a climate modeling approach should be conducted by accounting for the description of the terrestrial hydrological compartment.

Supplementary Information The online version contains supplementary material available at https://doi.org/10.1007/s00382-021-06044-9.

Acknowledgements This work was carried out with the financial support of the German Federal Ministry of Science and Education (BMBF, 01LL1701B), the China Scholarship Council and the German Science Foundation (DFG, AR 1183/2-1 and KU 2090/11-1). Ning Ma thanks the funding support from the National Natural Science Foundation of China (41801047). We are grateful for the data collection of the ECMWF data from https://www.ecmwf.int/, the HydroSHEDS data from http://hydrosheds.cr.usgs.gov, the CMFD data from https://doi. org/10.11888/AtmosphericPhysics.tpe.249369.file, the GLEAM data from https://www.gleam.eu, and the ESA CCI soil moisture data from https://esa-soilmoisture-cci.org. The ground observation data are available at the Chinese Meteorology Administration at http://data.cma. $\mathrm{cn} /$ and the West Data Center of China at http://westdc.westgis.ac.cn through registration. The WRF-Hydro Pre-processing tool is available online at https://ral.ucar.edu/projects/wrf_hydro/pre-processing-tools. The WRF and WRF-Hydro simulations were conducted at Leibniz Supercomputing Center (LRZ) SuperMUC and the High-Performance Computer in KIT/IMK-IFU. Finally, we also would like to thank Prof. Yanhong Gao (Fudan University) for her helpful comments. 
Funding Open Access funding enabled and organized by Projekt DEAL.

\section{Declarations}

Conflict of interest All the authors confirm that this work is original and has not been published previously, nor is it currently under consideration for publication elsewhere. All the authors listed have approved the submitted manuscript, and have no conflicts of interest to disclose.

Open Access This article is licensed under a Creative Commons Attribution 4.0 International License, which permits use, sharing, adaptation, distribution and reproduction in any medium or format, as long as you give appropriate credit to the original author(s) and the source, provide a link to the Creative Commons licence, and indicate if changes were made. The images or other third party material in this article are included in the article's Creative Commons licence, unless indicated otherwise in a credit line to the material. If material is not included in the article's Creative Commons licence and your intended use is not permitted by statutory regulation or exceeds the permitted use, you will need to obtain permission directly from the copyright holder. To view a copy of this licence, visit http://creativecommons.org/licenses/by/4.0/.

\section{References}

Arnault J, Knoche R, Wei J, Kunstmann H (2016a) Evaporation tagging and atmospheric water budget analysis with WRF: a regional precipitation recycling study for West Africa. Water Resour Res 52:1544-1567. https://doi.org/10.1002/2015WR017704

Arnault J, Wagner S, Rummler T et al (2016b) Role of runoff-infiltration partitioning and resolved overland flow on land-atmosphere feedbacks: a case study with the WRF-Hydro coupled modeling system for West Africa. J Hydrometeorol 17:1489-1516. https:// doi.org/10.1175/JHM-D-15-0089.1

Arnault J, Rummler T, Baur F et al (2018) Precipitation sensitivity to the uncertainty of terrestrial water flow in WRF-Hydro: an ensemble analysis for central Europe. J Hydrometeorol 19:10071025. https://doi.org/10.1175/JHM-D-17-0042.1

Arnault J, Wei J, Rummler T et al (2019) A joint soil-vegetation-atmospheric water tagging procedure with WRF-hydro: implementation and application to the case of precipitation partitioning in the Upper Danube River Basin. Water Resour Res 55:6217-6243. https://doi.org/10.1029/2019WR024780

Asharaf S, Dobler A, Ahrens B (2012) Soil moisture-precipitation feedback processes in the Indian Summer Monsoon Season. J Hydrometeorol 13:1461-1474. https://doi.org/10.1175/JHM-D-12-06.1

Avolio E, Federico S, Miglietta MM et al (2017) Sensitivity analysis of WRF model PBL schemes in simulating boundary-layer variables in southern Italy: an experimental campaign. Atmos Res 192:58-71. https://doi.org/10.1016/j.atmosres.2017.04.003

Betts AK, Silva Dias MAF (2010) Progress in understanding landsurface-atmosphere coupling from LBA research. J Adv Model Earth Syst 2:6. https://doi.org/10.3894/JAMES.2010.2.6

Braun SA, Tao W-K (2000) Sensitivity of high-resolution simulations of Hurricane Bob (1991) to planetary boundary layer parameterizations. Mon Weather Rev 128:3941-3961. https://doi.org/ 10.1175/1520-0493(2000)129\%3c3941:SOHRSO\%3e2.0.CO;2

Brown AR (1996) Evaluation of parametrization schemes for the convective boundary layer using large-eddy simulation results. Bound Layer Meteorol 81:167-200. https://doi.org/10.1007/ BF00119064
Burde GI, Zangvil A (2001) The estimation of regional precipitation recycling. Part I: review of recycling models. J Clim 14:24972508. https://doi.org/10.1175/1520-0442(2001)014\%3c2497: TEORPR\%3e2.0.CO;2

Butts M, Drews M, Larsen MAD et al (2014) Embedding complex hydrology in the regional climate system-dynamic coupling across different modelling domains. Adv Water Resour 74:166184. https://doi.org/10.1016/j.advwatres.2014.09.004

Campbell PC, Bash JO, Spero TL (2019) Updates to the Noah land surface model in WRF-CMAQ to improve simulated meteorology, air quality, and deposition. J Adv Model Earth Syst 11:231-256. https://doi.org/10.1029/2018MS001422

Chen F, Dudhia J (2001) Coupling an advanced land surface-hydrology model with the Penn State-NCAR MM5 modeling system. Part I: model implementation and sensitivity. Mon Weather Rev 129:569-585. https://doi.org/10.1175/1520-0493(2001)129\% 3c0569:CAALSH\%3e2.0.CO;2

Chen R, Liu J, Kang E et al (2015) Precipitation measurement intercomparison in the Qilian Mountains, north-eastern Tibetan Plateau. Cryosphere 9:1995-2008. https://doi.org/10.5194/ tc-9-1995-2015

Chen R, Han C, Liu J et al (2018a) Maximum precipitation altitude on the northern flank of the Qilian Mountains, northwest China. Hydrol Res 49:1696-1710. https://doi.org/10.2166/nh. 2018.121

Chen R, Wang G, Yang Y et al (2018b) Effects of cryospheric change on alpine hydrology: combining a model with observations in the upper reaches of the Hei River, China. J Geophys Res Atmos 123:3414-3442. https://doi.org/10.1002/2017JD027876

Cheng G, Li X, Zhao W et al (2014) Integrated study of the waterecosystem-economy in the Heihe River Basin. Natl Sci Rev 1:413-428. https://doi.org/10.1093/nsr/nwu017

Clark MP, Fan Y, Lawrence DM et al (2015) Improving the representation of hydrologic processes in Earth System Models. Water Resour Res 51:5929-5956. https://doi.org/10.1002/2015WR0170 96

Cohen AE, Cavallo SM, Coniglio MC, Brooks HE (2015) A review of planetary boundary layer parameterization schemes and their sensitivity in simulating Southeastern U.S. Cold Season Severe Weather Environments. Weather Forecast 30:591-612. https:// doi.org/10.1175/WAF-D-14-00105.1

Cook BI, Bonan GB, Levis S (2006) Soil moisture feedbacks to precipitation in southern Africa. J Clim 19:4198-4206. https://doi. org/10.1175/JCLI3856.1

Crétat J, Pohl B, Richard Y, Drobinski P (2012) Uncertainties in simulating regional climate of Southern Africa: sensitivity to physical parameterizations using WRF. Clim Dyn 38:613-634. https://doi. org/10.1007/s00382-011-1055-8

Davison JH, Hwang HT, Sudicky EA et al (2018) Full coupling between the atmosphere, surface, and subsurface for integrated hydrologic simulation. J Adv Model Earth Syst 10:43-53. https:// doi.org/10.1002/2017MS001052

Derbyshire SH, Beau I, Bechtold P et al (2004) Sensitivity of moist convection to environmental humidity. Q J R Meteorol Soc 130:3055-3079. https://doi.org/10.1256/qj.03.130

Dominguez F, Miguez-Macho G, Hu H (2016) WRF with water vapor tracers: a study of moisture sources for the north American monsoon. J Hydrometeorol 17(7):1915-1927. https://doi.org/ 10.1175/JHM-D-15-0221.1.

Duan H, Li Y, Zhang T et al (2018) Evaluation of the forecast accuracy of near-surface temperature and wind in Northwest China based on the WRF Model. J Meteorol Res 32:469-490. https://doi.org/ $10.1007 /$ s13351-018-7115-9

Dudhia J (1989) Numerical study of convection observed during the Winter monsoon experiment using a mesoscale two-dimensional 
model. J Atmos Sci 46:3077-3107. https://doi.org/10.1175/15200469(1989)046\%3c3077:NSOCOD\%3e2.0.CO;2

Eltahir EAB, Bras RL (1996) Precipitation recycling. Rev Geophys 34:367-378. https://doi.org/10.1029/96RG01927

Fan Y, Clark M, Lawrence DM, Swenson S, Band LE, Brantley SL et al (2019) Hillslope hydrology in global change research and Earth system modeling. Water Resour Res 55:1737-1772. https://doi. org/10.1029/2018WR023903

Fosser G, Khodayar S, Berg P (2014) Benefit of convection permitting climate model simulations in the representation of convective precipitation. Clim Dyn 44(1-2):45-60. https://doi.org/10.1007/ s00382-014-2242-1

Froidevaux P, Schlemmer L, Schmidli J, Langhans W, Schär C (2014) Influence of the background wind on the local soil moistureprecipitation feedback. J Atmos Sci 71(2):782-799. https://doi. org/10.1175/JAS-D-13-0180.1

Gao Y, Cheng G, Cui W et al (2006) Coupling of enhanced land surface hydrology with atmospheric mesoscale model and its application in Heihe River Basin. Adv Earth Sci 21:1283-1292 (in Chinese)

Gao Y, Chen F, Barlage M et al (2008) Enhancement of land surface information and its impact on atmospheric modeling in the Heihe River Basin, northwest China. J Geophys Res 113:D20S90. https://doi.org/10.1029/2008JD010359

Gao Y, Xu J, Chen D (2015) Evaluation of WRF mesoscale climate simulations over the Tibetan Plateau during 1979-2011. J Clim 28:2823-2841. https://doi.org/10.1175/JCLI-D-14-00300.1

Gao B, Qin Y, Wang Y et al (2016) Modeling ecohydrological processes and spatial patterns in the upper Heihe basin in China. Forests 7:1-21. https://doi.org/10.3390/f7010010

Gao Y, Chen F, Miguez-Macho G, Li X (2020) Understanding precipitation recycling over the Tibetan Plateau using tracer analysis with WRF. Clim Dyn. https://doi.org/10.1007/ s00382-020-05426-9

García-Díez M, Fernández J, Fita L, Yagüe C (2013) Seasonal dependence of WRF model biases and sensitivity to PBL schemes over Europe. Q J R Meteorol Soc 139:501-514. https://doi.org/10. 1002/qj.1976

Gasper F, Goergen K, Shrestha P et al (2014) Implementation and scaling of the fully coupled Terrestrial Systems Modeling Platform (TerrSysMP v1.0) in a massively parallel supercomputing environment - a case study on JUQUEEN (IBM Blue Gene/Q). Geosci Model Dev 7:2531-2543. https://doi.org/10.5194/ gmd-7-2531-2014

Gochis D, Yu W, Yates D (2015) The NCAR WRF-Hydro technical description and user's guide, version 3.0. https://doi.org/10.5065/ D6DN43TQ

Gómez-Navarro JJ, Raible CC, Dierer S (2015) Sensitivity of the WRF model to PBL parametrisations and nesting techniques: evaluation of wind storms over complex terrain. Geosci Model Dev 8:3349-3363. https://doi.org/10.5194/gmd-8-3349-2015

Gruber A, Scanlon T, van der Schalie R, Wagner W, Dorigo W (2019) Evolution of the ESA CCI SOIL MOISTURE climate data records and their underlying merging methodology. Earth Syst Sci Data 11:717-739. https://doi.org/10.5194/essd-11-717-2019

Gunwani P, Mohan M (2017) Sensitivity of WRF model estimates to various PBL parameterizations in different climatic zones over India. Atmos Res 194:43-65. https://doi.org/10.1016/j.atmosres. 2017.04.026

Gupta H, Kling H, Yilmaz KK, Martinez GF (2009) Decomposition of the mean squared error and NSE performance criteria: implications for improving hydrological modelling. J Hydrol 377:80-91. https://doi.org/10.1016/j.jhydrol.2009.08.003

He J, Yang K, Tang W et al (2020) The first high-resolution meteorological forcing dataset for land process studies over China. Sci Data 7:25. https://doi.org/10.1038/s41597-020-0369-y
Hong S, Lim J (2006) The WRF single-moment 6-class microphysics scheme (WSM6). J Korean Meteorol Soc 42:129-151

Hong S-Y, Pan H-L (1996) Nonlocal boundary layer vertical diffusion in a medium-range forecast model. Mon Weather Rev 124:2322 2339. https://doi.org/10.1175/1520-0493(1996)124\%3c2322: NBLVDI\%3e2.0.CO;2

Hong S-Y, Noh Y, Dudhia J (2006) A new vertical diffusion package with an explicit treatment of entrainment processes. Mon Weather Rev 134:2318-2341. https://doi.org/10.1175/MWR31 99.1

Hu X-M, Nielsen-Gammon JW, Zhang F (2010) Evaluation of three planetary boundary layer schemes in the WRF model. J Appl Meteorol Climatol 49:1831-1844. https://doi.org/10.1175/2010J AMC2432.1

Immerzeel WW, van Beek LPH, Bierkens MFP (2010) Climate change will affect the asian water towers. Science 328:1382-1385. https://doi.org/10.1126/science.1183188

Insua-Costa D, Miguez-Macho G (2018) A new moisture tagging capability in the weather research and forecasting model: formulation, validation and application to the 2014 Great Lake-effect snowstorm. Earth Syst Dyn 9:167-185. https://doi.org/10.5194/ esd-9-167-2018

Janjić ZI (1994) The step-mountain eta coordinate model: further developments of the convection, viscous sublayer, and turbulence closure schemes. Mon Weather Rev 122:927-945. https://doi. org/10.1175/1520-0493(1994)122\%3c0927:TSMECM\%3e2.0. $\mathrm{CO} ; 2$

Karki R, ul Hasson S, Gerlitz L, Schickhoff U, Scholten T, Böhner J (2017) Quantifying the added value of convection-permitting climate simulations in complex terrain: a systematic evaluation of WRF over the Himalayas. Earth Syst Dyn 8(3):507-528. https:// doi.org/10.5194/esd-8-507-2017

Kerandi N, Arnault J, Laux P et al (2018) Joint atmospheric-terrestrial water balances for East Africa: a WRF-Hydro case study for the upper Tana River basin. Theor Appl Climatol 131:1337-1355. https://doi.org/10.1007/s00704-017-2050-8

Klein C, Heinzeller D, Bliefernicht J, Kunstmann H (2015) Variability of West African monsoon patterns generated by a WRF multiphysics ensemble. Clim Dyn 45:2733-2755. https://doi.org/10. 1007/s00382-015-2505-5

Knist S, Goergen K, Buonomo E et al (2017) Land-atmosphere coupling in EURO-CORDEX evaluation experiments. J Geophys Res Atmos 122:79-103. https://doi.org/10.1002/2016JD025476

Knist S, Goergen K, Simmer C (2018) Evaluation and projected changes of precipitation statistics in convection-permitting WRF climate simulations over Central Europe. Clim Dyn. https://doi. org/10.1007/s00382-018-4147-x

Knoche HR, Kunstmann H (2013) Tracking atmospheric water pathways by direct evaporation tagging: a case study for West Africa. J Geophys Res Atmos 118:12345-12358. https://doi.org/10. 1002/2013JD019976

Kokkonen T, Koivusalo H, Karvonen T et al (2004) Exploring streamflow response to effective rainfall across event magnitude scale. Hydrol Process 18:1467-1486. https://doi.org/10.1002/hyp.1423

Koster RD, Mahanama SPP, Yamada TJ et al (2010) Contribution of land surface initialization to subseasonal forecast skill: First results from a multi-model experiment. Geophys Res Lett. https://doi.org/10.1029/2009GL041677

Koster RD, Chang Y, Wang H, Schubert HD (2016) Impacts of local soil moisture anomalies on the atmospheric circulation and on remote surface meteorological fields during boreal summer: a comprehensive analysis over North America. J Clim 29:73457364. https://doi.org/10.1175/JCLI-D-16-0192.1

Lahmers TM, Castro CL, Hazenberg P (2020) Effects of lateral flow on the convective environment in a coupled hydrometeorological 
modeling system in a semiarid environment. J Hydrometeorol 21(4):615-642. https://doi.org/10.1175/JHM-D-19-0100.1

Larsen MAD, Refsgaard JC, Drews M et al (2014) Results from a full coupling of the HIRHAM regional climate model and the MIKE SHE hydrological model for a Danish catchment. Hydrol Earth Syst Sci 18:4733-4749. https://doi.org/10.5194/ hess-18-4733-2014

Laux P, Nguyen PNB, Cullmann J et al (2017) How many RCM ensemble members provide confidence in the impact of land-use land cover change? Int J Climatol 37:2080-2100. https://doi.org/10. $1002 /$ joc. 4836

Lehner B, Verdin K, Jarvis A (2008) New global hydrography derived from spaceborne elevation data. EOS Trans Am Geophys Union 89:93. https://doi.org/10.1029/2008EO100001

Li X, Cheng G, Liu S et al (2013) Heihe watershed allied telemetry experimental research (HiWater) scientific objectives and experimental design. Bull Am Meteorol Soc 94:1145-1160. https://doi. org/10.1175/BAMS-D-12-00154.1

Li Z, Gao Y, Wang Y et al (2015) Can monsoon moisture arrive in the Qilian Mountains in summer? Quatern Int 358:113-125. https:// doi.org/10.1016/j.quaint.2014.08.046

Li L, Gochis DJ, Sobolowski S, Mesquita MDS (2017) Evaluating the present annual water budget of a Himalayan headwater river basin using a high-resolution atmosphere-hydrology model. J Geophys Res Atmos 122:4786-4807. https://doi.org/10.1002/ 2016JD026279

Li X, Cheng G, Ge Y et al (2018a) Hydrological cycle in the Heihe River Basin and its implication for water resource management in Endorheic Basins. J Geophys Res Atmos 123:890-914. https://doi.org/10.1002/2017JD027889

Li X, Cheng G, Lin H et al (2018b) Watershed system model: the essentials to model complex human-nature system at the river basin scale. J Geophys Res Atmos 123:3019-3034. https://doi. org/10.1002/2017JD028154

Li Z, Li Q, Wang J et al (2020) Impacts of projected climate change on runoff in upper reach of Heihe River basin using climate elasticity method and GCMs. Sci Total Environ 716:137072. https://doi.org/10.1016/j.scitotenv.2020.137072

Luo K, Tao F, Moiwo JP, Xiao D (2016) Attribution of hydrological change in Heihe River Basin to climate and land use change in the past three decades. Sci Rep 6:33704. https://doi.org/10. 1038/srep33704

Ma N, Wang N, Zhao L et al (2014) Observation of mega-dune evaporation after various rain events in the hinterland of Badain Jaran Desert, China. Chin Sci Bull 59:162-170. https://doi. org/10.1007/s11434-013-0050-3

Ma N, Niu G-Y, Xia Y, Cai X, Zhang Y, Ma Y, Fang Y (2017) A systematic evaluation of Noah-MP in simulating land-atmosphere energy, water, and carbon exchanges over the continental United States. J Geophys Res Atmos 122(22):12245-12268. https://doi.org/10.1002/2017JD027597

Ma N, Szilagyi J, Zhang Y, Liu W (2019) Complementary-relationship-based modeling of terrestrial evapotranspiration across China during 1982-2012: validations and spatiotemporal analyses. J Geophys Res Atmos 124(8):4326-4351. https://doi.org/ 10.1029/2018JD029850

Martens B, Miralles DG, Lievens H et al (2017) GLEAM v3: satellite-based land evaporation and root-zone soil moisture. Geosci Model Dev 10:1903-1925. https://doi.org/10.5194/ gmd-10-1903-2017

Meng X, Lü S, Zhang T et al (2009) Numerical simulations of the atmospheric and land conditions over the Jinta oasis in Northwestern China with satellite-derived land surface parameters. J Geophys Res 114:D06114. https://doi.org/10.1029/2008J D010360
Mlawer EJ, Taubman SJ, Brown PD et al (1997) Radiative transfer for inhomogeneous atmospheres: RRTM, a validated correlated-k model for the longwave. J Geophys Res 102:1666316682. https://doi.org/10.1029/97JD00237

Ning L, Zhan C, Luo Y et al (2019) A review of fully coupled atmosphere-hydrology simulations. J Geog Sci 29:465-479. https:// doi.org/10.1007/s11442-019-1610-5

Pan X, Li X, Shi X et al (2012) Dynamic downscaling of near-surface air temperature at the basin scale using WRF-a case study in the Heihe River Basin, China. Front Earth Sci 6:314-323. https://doi.org/10.1007/s11707-012-0306-2

Pan X, Li X, Yang K et al (2014) Comparison of downscaled precipitation data over a mountainous watershed: a case study in the Heihe River Basin. J Hydrometeorol 15:1560-1574. https:// doi.org/10.1175/JHM-D-13-0202.1

Pan X, Li X, Cheng G, Chen R, Hsu K (2017) Impact analysis of climate change on snow over a complex mountainous region using weather research and forecast model (WRF) simulation and moderate resolution imaging spectroradiometer data (MODIS)-terra fractional snow cover products. Remote Sens 9(8):774. https://doi.org/10.3390/rs9080774

Pepin N, Bradley RS, Diaz HF et al (2015) Elevation-dependent warming in mountain regions of the world. Nat Clim Change 5:424-430. https://doi.org/10.1038/nclimate2563

Pleim JE (2007) A combined local and nonlocal closure model for the atmospheric boundary layer. Part I: model description and testing. J Appl Meteorol Climatol 46:1383-1395. https://doi. org/10.1175/JAM2539.1

Powers JG, Klemp JB, Skamarock WC et al (2017) The weather research and forecasting model: overview, system efforts, and future directions. Bull Am Meteorol Soc 98:1717-1737. https:// doi.org/10.1175/BAMS-D-15-00308.1

Prein AF, Langhans W, Fosser G, Ferrone A, Ban N, Goergen K et al (2015) A review on regional convection-permitting climate modeling: demonstrations prospects and challenges. Rev Geophys 53(2):323-361. https://doi.org/10.1002/2014RG000475

Qiu L, Im E-S, Hur J, Shim K-M (2019) Added value of very high resolution climate simulations over South Korea using WRF modeling system. Clim Dyn. https://doi.org/10.1007/ s00382-019-04992-x

Ran YH, Li X, Lu L, Li ZY (2012) Large-scale land cover mapping with the integration of multi-source information based on the Dempster-Shafer theory. Int J Geogr Inf Sci 26:169-191. https:// doi.org/10.1080/13658816.2011.577745

Rasmussen SH, Christensen JH, Drews M et al (2012) Spatial-scale characteristics of precipitation simulated by regional climate models and the implications for hydrological modeling. J Hydrometeorol. https://doi.org/10.1175/jhm-d-12-07.1

Ruan H, Zou S, Yang D et al (2017) Runoff simulation by SWAT model using high-resolution gridded precipitation in the Upper Heihe River Basin, Northeastern Tibetan Plateau. Water 9:866. https:// doi.org/10.3390/w9110866

Rummler T, Arnault J, Gochis D, Kunstmann H (2019) Role of lateral terrestrial water flow on the regional water cycle in a complex terrain region: investigation with a fully coupled model system. J Geophys Res Atmos 124:507-529. https://doi.org/10.1029/ 2018JD029004

Santanello JA, Dirmeyer PA, Ferguson CR et al (2018) Land-atmosphere interactions: the LoCo perspective. Bull Am Meteorol Soc 99:1253-1272. https://doi.org/10.1175/BAMS-D-17-0001.1

Schär C, Lüthi D, Beyerle U, Heise E (1999) The soil-precipitation feedback: a process study with a regional climate model. J Clim 12:722-741. https://doi.org/10.1175/1520-0442(1999)012\% 3c0722:TSPFAP\%3e2.0.CO;2

Senatore A, Mendicino G, Gochis DJ et al (2015) Fully coupled atmosphere-hydrology simulations for the central Mediterranean: 
impact of enhanced hydrological parameterization for short and long time scales. J Adv Model Earth Syst 7:1693-1715. https:// doi.org/10.1002/2015MS000510

Shrestha P, Sulis M, Masbou M et al (2014) A scale-consistent terrestrial systems modeling platform based on COSMO, CLM, and ParFlow. Mon Weather Rev 142:3466-3483. https://doi.org/10.1175/ MWR-D-14-00029.1

Skamarock WC, Klemp JB (2008) A time-split nonhydrostatic atmospheric model for weather research and forecasting applications. J Comput Phys 227:3465-3485. https://doi.org/10.1016/j.jcp.2007.01.037

Smirnova TG, Brown JM, Benjamin SG, Kenyon JS (2016) Modifications to the rapid update cycle land surface model (RUC LSM) available in the weather research and forecasting (WRF) model. Mon Weather Rev 144:1851-1865. https://doi.org/10.1175/MWR-D-15-0198.1

Sodemann H, Wernli H, Schwierz C (2009) Sources of water vapour contributing to the Elbe flood in August 2002 - a tagging study in a mesoscale model. Q J R Meteorol Soc 135:205-223. https://doi.org/ 10.1002/qj.374

Solman SA, Blázquez J (2019) Multiscale precipitation variability over South America: analysis of the added value of CORDEX RCM simulations. Clim Dyn 53:1547-1565. https://doi.org/10.1007/ s00382-019-04689-1

Srinivas CV, Venkatesan R, Bagavath Singh A (2007) Sensitivity of mesoscale simulations of land-sea breeze to boundary layer turbulence parameterization. Atmos Environ. https://doi.org/10.1016/j.atmos env.2006.11.027

Su H, Xiong Z, Yan X et al (2017) Comparison of monthly rainfall generated from dynamical and statistical downscaling methods: a case study of the Heihe River Basin in China. Theor Appl Climatol 129:437-444. https://doi.org/10.1007/s00704-016-1771-4

Taylor CM, Birch CE, Parker DJ, Dixon N, Guichard F, Nikulin G, Lister G (2013) Modeling soil moisture-precipitation feedback in the Sahel: importance of spatial scale versus convective parameterization. Geophys Res Lett 40(23):6213-6218. https://doi.org/10.1002/ 2013GL058511

Trenberth KE (1999) Atmospheric moisture recycling: role of advection and local evaporation. J Clim 12:1368-1381. https://doi.org/10.1175/ 1520-0442(1999)012\%3c1368:AMRROA\%3e2.0.CO;2

van der Ent RJ, Tuinenburg OA, Knoche H-R et al (2013) Should we use a simple or complex model for moisture recycling and atmospheric moisture tracking? Hydrol Earth Syst Sci 17:4869-4884. https://doi. org/10.5194/hess-17-4869-2013

Vörösmarty CJ, Green P, Salisbury J, Lammers RB (2000) Global water resources: Vulnerability from climate change and population growth. Science. https://doi.org/10.1126/science.289.5477.284

Wang K, Cheng G, Xiao H et al (2004) The westerly fluctuation and water vapor transport over the Qilian-Heihe valley. Sci China Ser D Earth Sci 47:32-38. https://doi.org/10.1360/04yd0004

Wang L, Chen R, Song Y et al (2018a) Precipitation-altitude relationships on different timescales and at different precipitation magnitudes in the Qilian Mountains. Theor Appl Climatol 134:875-884. https:// doi.org/10.1007/s00704-017-2316-1

Wang X, Pang G, Yang M et al (2018b) Precipitation changes in the Qilian Mountains associated with the shifts of regional atmospheric water vapour during 1960-2014. Int J Climatol 38:4355-4368. https://doi. org/10.1002/joc.5673

Wei J, Knoche HR, Kunstmann H (2015) Contribution of transpiration and evaporation to precipitation: an ET-Tagging study for the Poyang Lake region in Southeast China. J Geophys Res Atmos 120:68456864. https://doi.org/10.1002/2014JD022975

Wei J, Su H, Yang ZL (2016) Impact of moisture flux convergence and soil moisture on precipitation: a case study for the southern United States with implications for the globe. Clim Dyn 46:467481. https://doi.org/10.1007/s00382-015-2593-2
Wen X, Lu S, Jin J (2012) Integrating remote sensing data with WRF for improved simulations of oasis effects on local weather processes over an arid region in Northwestern China. J Hydrometeorol 13:573-587. https://doi.org/10.1175/JHM-D-10-05001.1

Woodhams BJ, Birch CE, Marsham JH, Bain CL, Roberts NM, Boyd DFA (2018) What is the added value of a convection-permitting model for forecasting extreme rainfall over tropical East Africa? Mon Weather Rev 146(9):2757-2780. https://doi.org/10.1175/ MWR-D-17-0396.1

Wu B, Zhu W, Yan N et al (2020) Regional actual evapotranspiration estimation with land and meteorological variables derived from multi-source satellite data. Remote Sensing 12:332. https://doi. org/10.3390/rs12020332

Xie B, Fung JCH, Chan A, Lau A (2012) Evaluation of nonlocal and local planetary boundary layer schemes in the WRF model. J Geophys Res Atmos. https://doi.org/10.1029/2011JD017080

Xiong Z, Yan XD (2013) Building a high-resolution regional climate model for the Heihe River Basin and simulating precipitation over this region. Chin Sci Bull 58:4670-4678. https://doi.org/ 10.1007/s11434-013-5971-3

Yang Z, Dominguez F (2019) Investigating land surface effects on the moisture transport over South America with a moisture tagging model. J Clim 32:6627-6644. https://doi.org/10.1175/ JCLI-D-18-0700.1

Yang D, Gao B, Jiao Y et al (2015) A distributed scheme developed for eco-hydrological modeling in the upper Heihe River. Sci China Earth Sci 58:36-45. https://doi.org/10.1007/s11430-014-5029-7

Yang Y, Tang J, Xiong Z, Dong X (2017b) Evaluation of high-resolution gridded precipitation data in arid and semiarid regions: Heihe River Basin, Northwest China. J Hydrometeorol 18:30753101. https://doi.org/10.1175/JHM-D-16-0252.1

Yang X, Yong B, Ren L et al (2017a) Multi-scale validation of GLEAM evapotranspiration products over China via ChinaFLUX ET measurements. Int J Remote Sens 38:5688-5709. https://doi. org/10.1080/01431161.2017.1346400

Yin J, Albertson JD, Rigby JR, Porporato A (2015) Land and atmospheric controls on initiation and intensity of moist convection: CAPE dynamics and LCL crossings. Water Resour Res 51:84768493. https://doi.org/10.1002/2015WR017286

Yucel I, Onen A, Yilmaz KK, Gochis DJ (2015) Calibration and evaluation of a flood forecasting system: utility of numerical weather prediction model, data assimilation and satellite-based rainfall. J Hydrol 523:49-66. https://doi.org/10.1016/j.jhydrol.2015.01.042

Zabel F, Mauser W (2013) 2-way coupling the hydrological land surface model PROMET with the regional climate model MM5. Hydrol Earth Syst Sci 17:1705-1714. https://doi.org/10.5194/ hess-17-1705-2013

Zabel F, Mauser W, Marke T et al (2012) Inter-comparison of two landsurface models applied at different scales and their feedbacks while coupled with a regional climate model. Hydrol Earth Syst Sci 16:1017-1031. https://doi.org/10.5194/hess-16-1017-2012

Zhang A, Liu W, Yin Z et al (2016) How will climate change affect the water availability in the Heihe River Basin, Northwest China? J Hydrometeorol 17:1517-1542. https://doi.org/10.1175/ JHM-D-15-0058.1

Zhang X, Xiong Z, Zheng J, Ge Q (2018) High-resolution precipitation data derived from dynamical downscaling using the WRF model for the Heihe River Basin, northwest China. Theor Appl Climatol 131:1249-1259. https://doi.org/10.1007/s00704-017-2052-6

Zhang Z, Arnault J, Wagner S et al (2019) Impact of lateral terrestrial water flow on land-atmosphere interactions in the Heihe River Basin in China: fully coupled modeling and precipitation recycling analysis. J Geophys Res Atmos 124:8401-8423. https://doi. org/10.1029/2018JD030174 
Zheng D, van der Velde R, Su Z et al (2017) Evaluation of Noah frozen soil parameterization for application to a Tibetan Meadow ecosystem. J Hydrometeorol 18:1749-1763. https://doi.org/10. 1175/JHM-D-16-0199.1
Publisher's Note Springer Nature remains neutral with regard to jurisdictional claims in published maps and institutional affiliations. 